\title{
The Challenge of Preparing Teams for the European Robotics League: Emergency
}

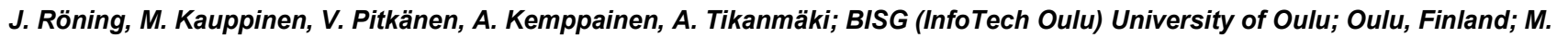

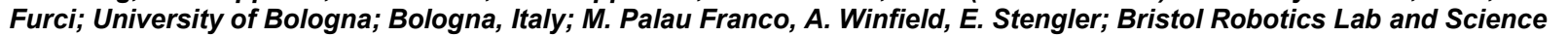

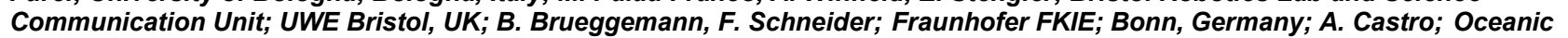

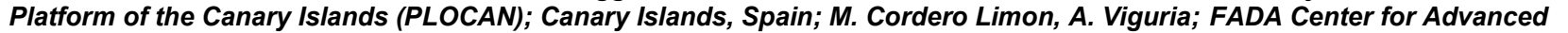

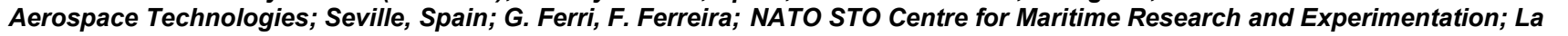

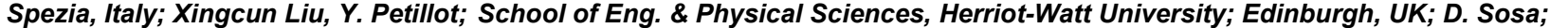

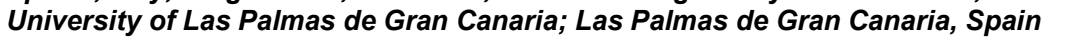

\begin{abstract}
ERL Emergency is an outdoor multi-domain robotic competition inspired by the 2011 Fukushima accident. The ERL Emergency Challenge requires teams of land, underwater and flying robots to work together to survey the scene, collect environmental data, and identify critical hazards. To prepare teams for this multidisciplinary task a series of summer schools and workshops have been arranged. In this paper the challenges and hands-on results of bringing students and researchers collaborating successfully in unknown environments and in new research areas are explained. As a case study results from the euRathlon/SHERPA workshop 2015 in Oulu are given.
\end{abstract}

\section{Introduction}

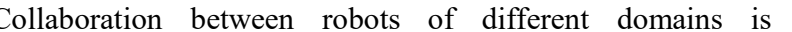

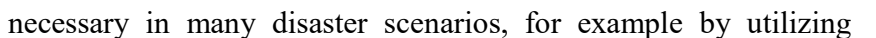

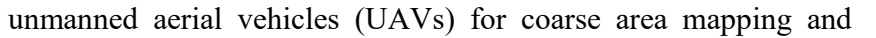

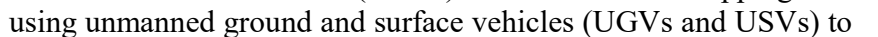

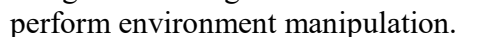

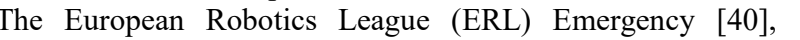

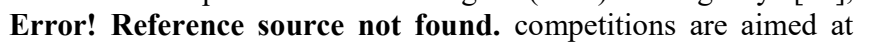

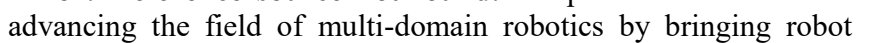

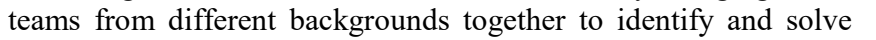

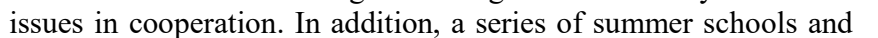

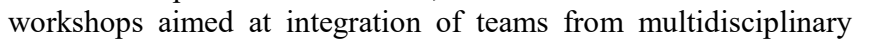
ए

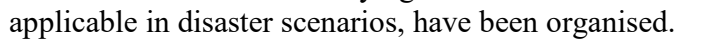

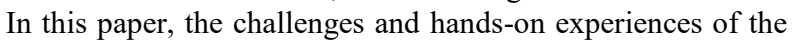

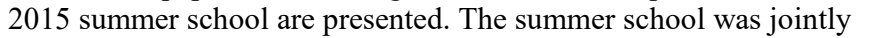

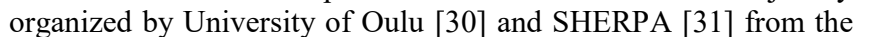

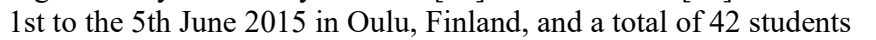
ए

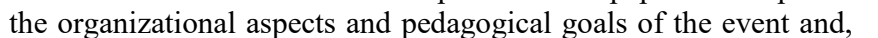

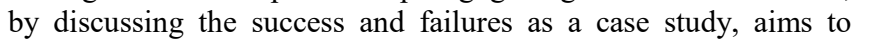

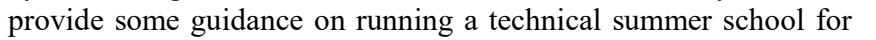

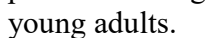

\section{Motivation for ERL Emergency and SHERPA}

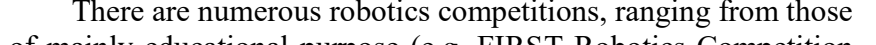

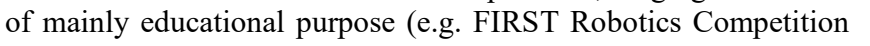

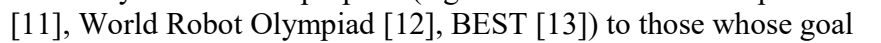
ए

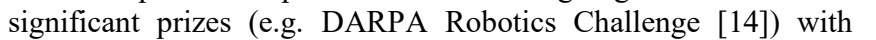

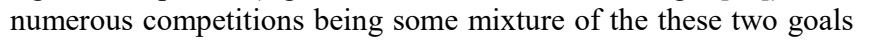

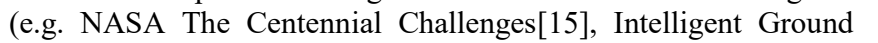

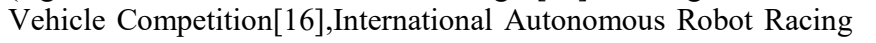

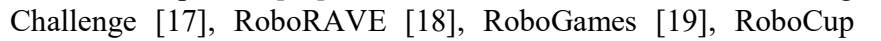
ए

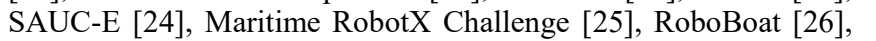

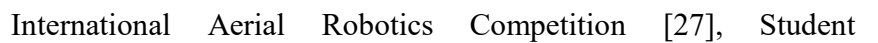

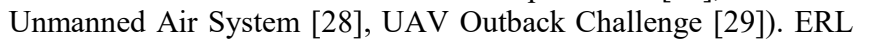

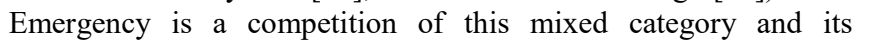

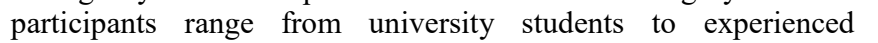

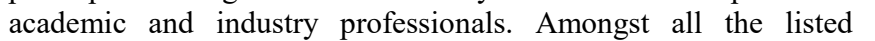

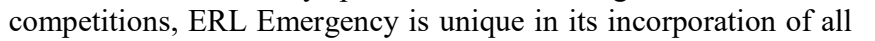

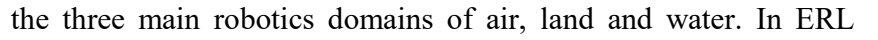

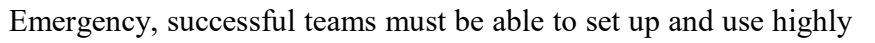

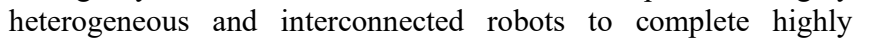

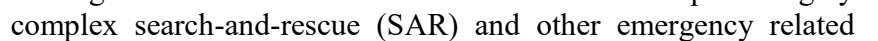

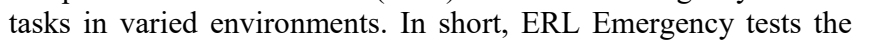

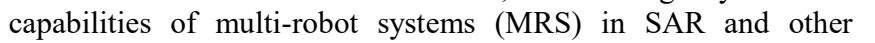

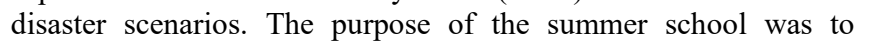

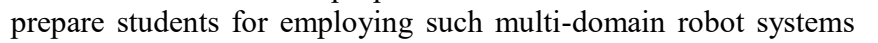

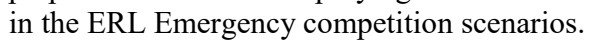

SHERPA, or "Smart collaboration between Humans and

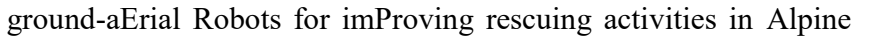

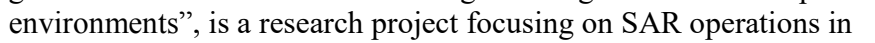

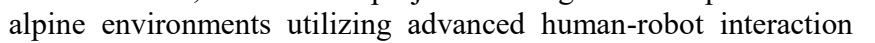

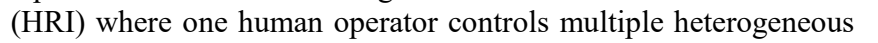

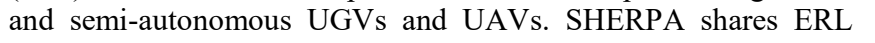
$\square \square$ rrgency's concept of utilization of MRSs and as such was a

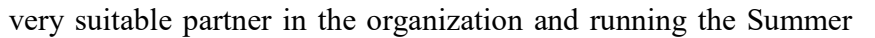

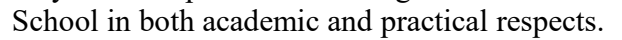

The motivation behind ERL Emergency's and SHERPA's

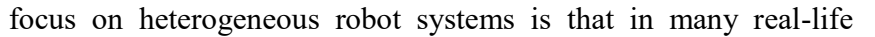

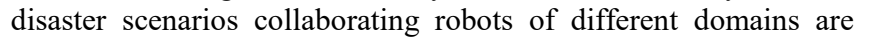

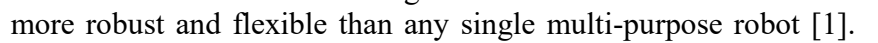

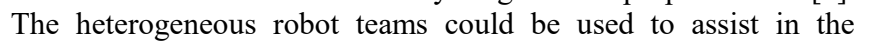

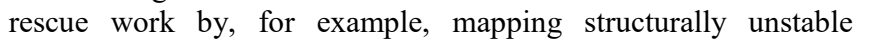

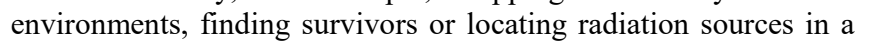

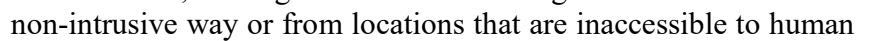

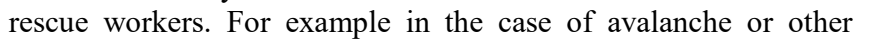

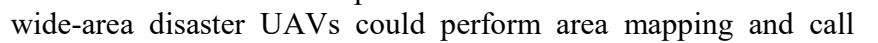

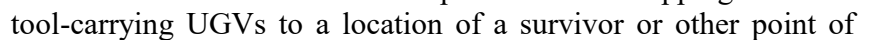
ए

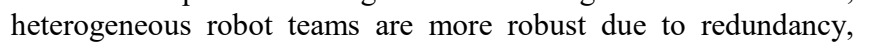

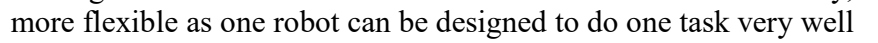

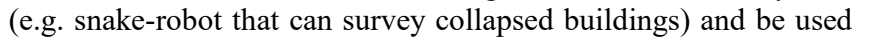

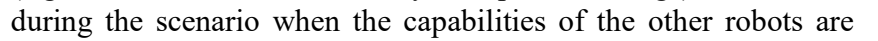

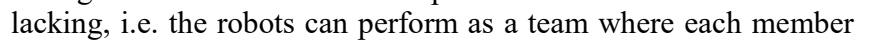

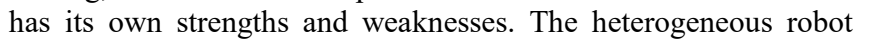

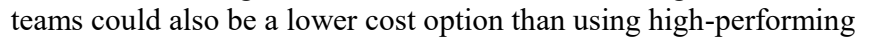

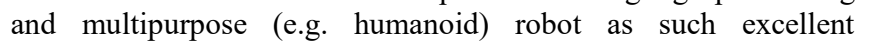

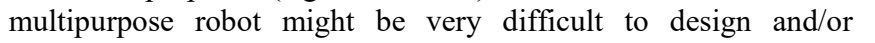

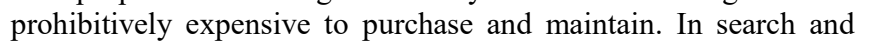

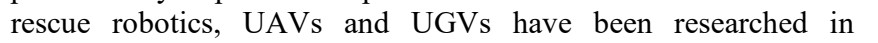

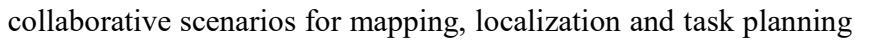

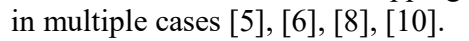




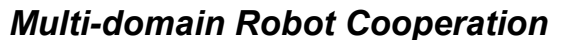

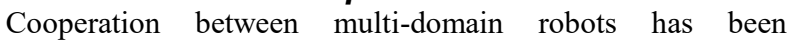

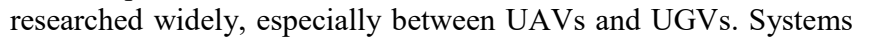

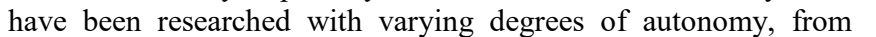

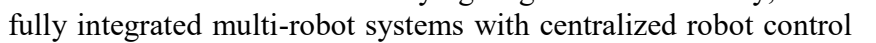

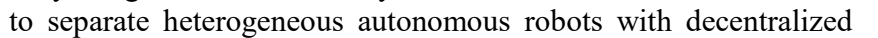

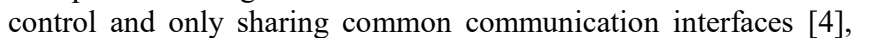

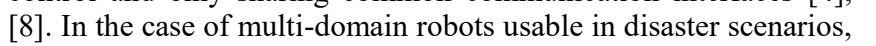

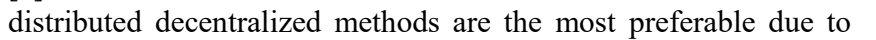

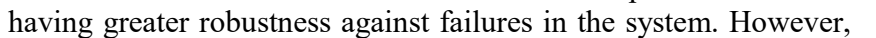

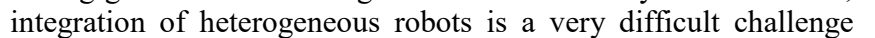

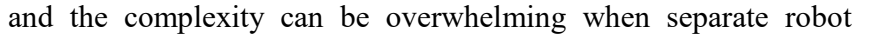

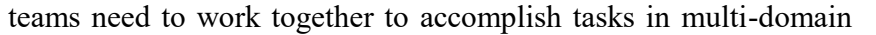

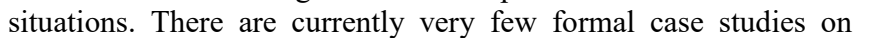

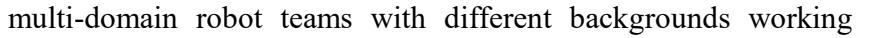

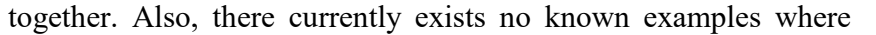

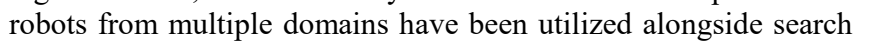

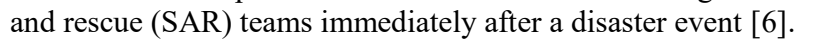

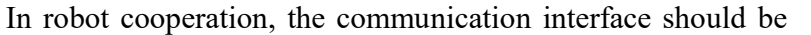

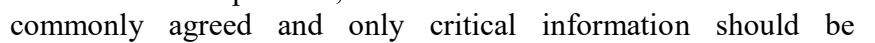

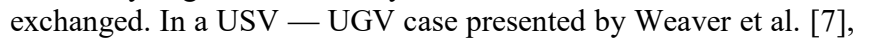

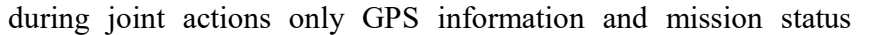

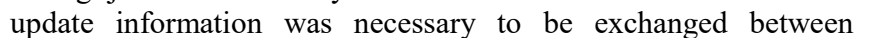

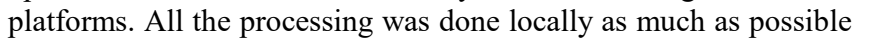

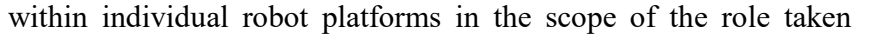

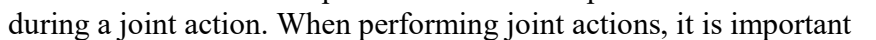
ए

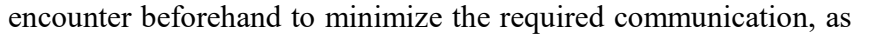

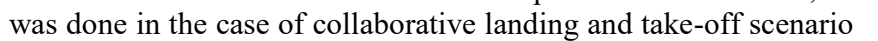

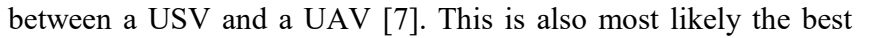

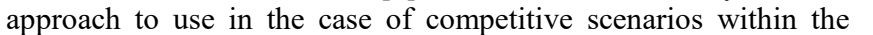

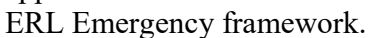

\section{Summer School inspired by the ERL Emergency Competitions}

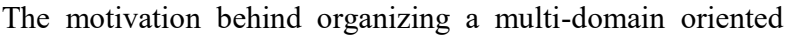

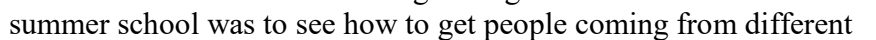

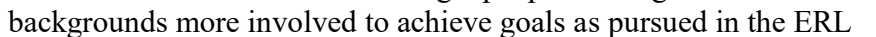

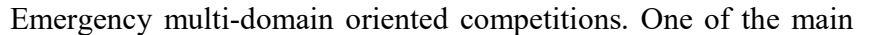

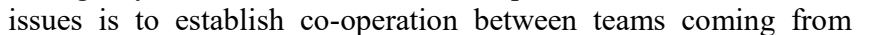

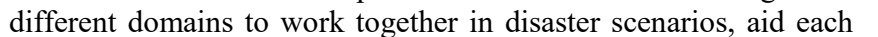

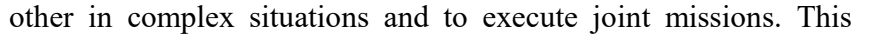

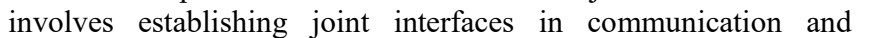

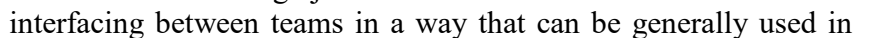

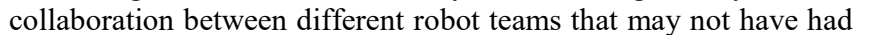

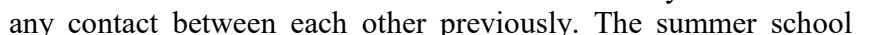

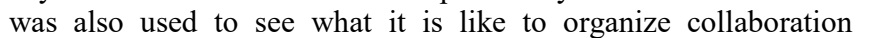

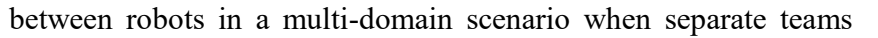

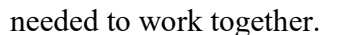

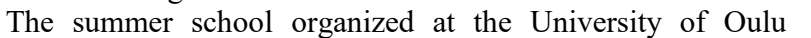

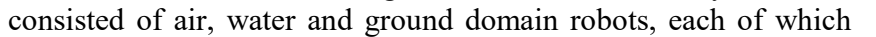
एம

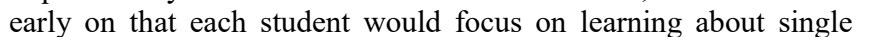

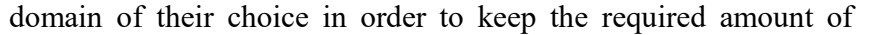

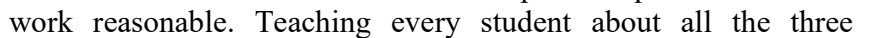

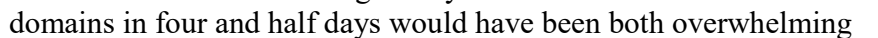

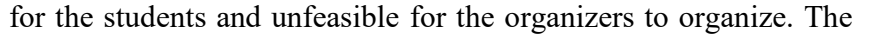

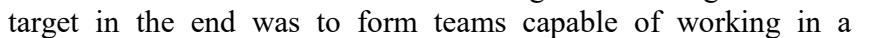

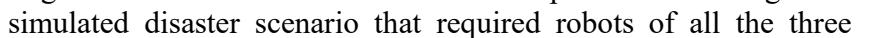

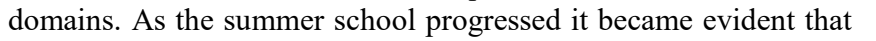

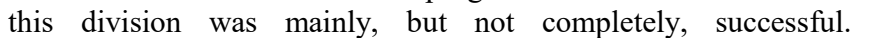

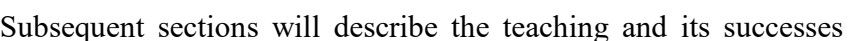

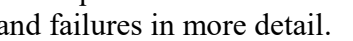

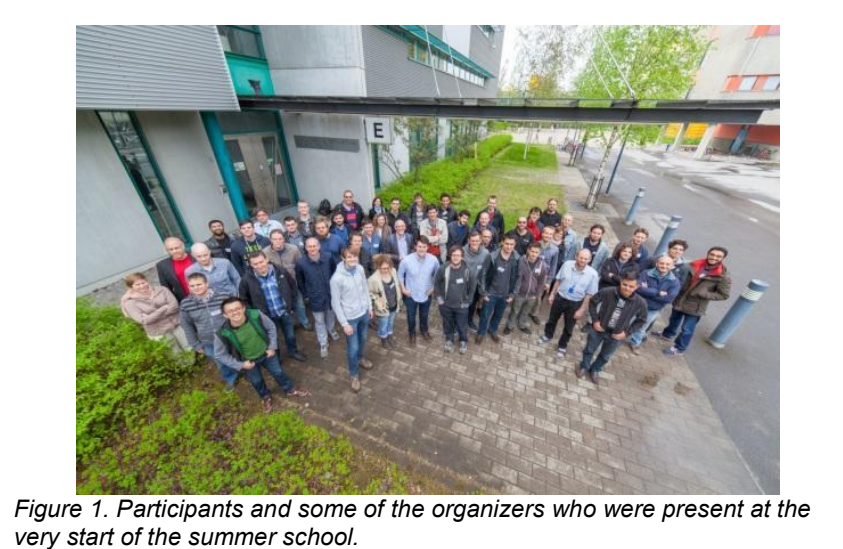

\section{Organization of the Exercises}

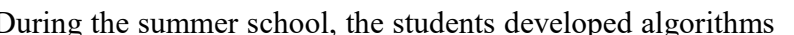
ए

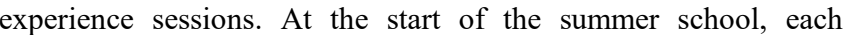
student chose which of three domains' practical sessions he or she

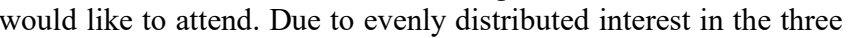

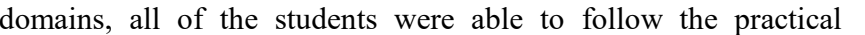

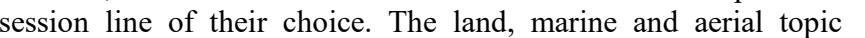

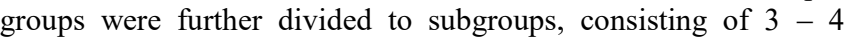

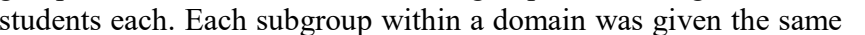

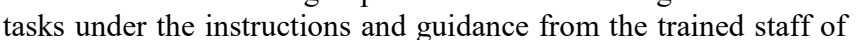
the university of Oulu and SHERPA. The results of each group's

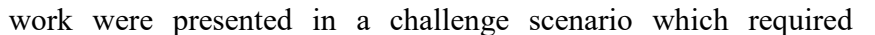

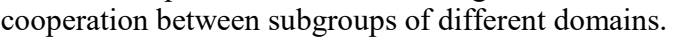

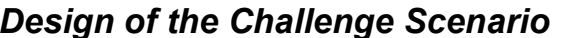

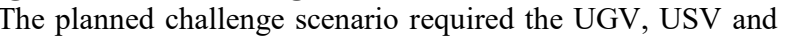

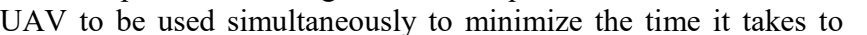

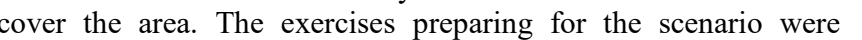

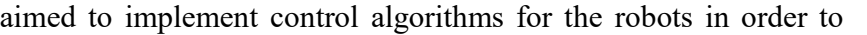

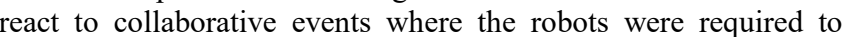

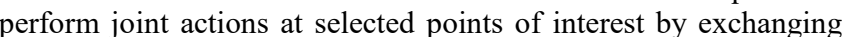

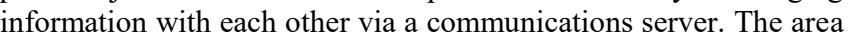

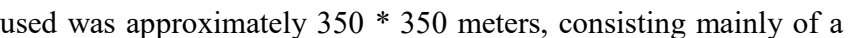

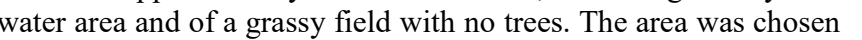

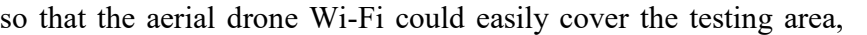

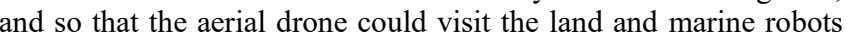

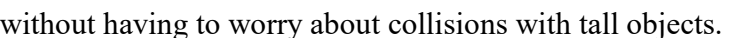

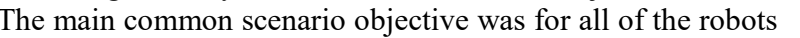

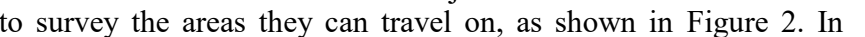

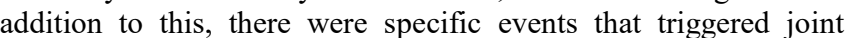

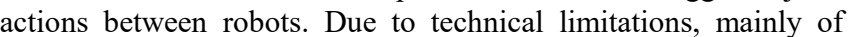

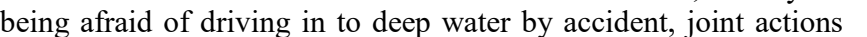

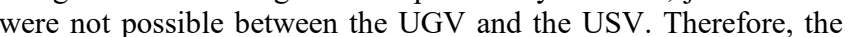

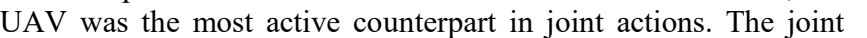

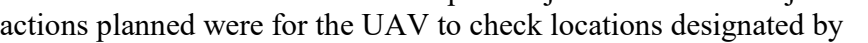

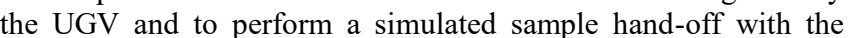

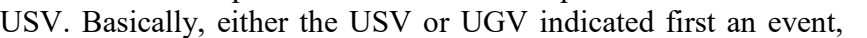

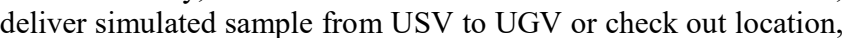

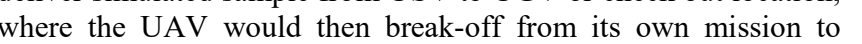

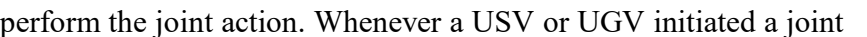

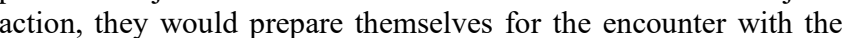




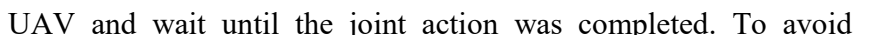

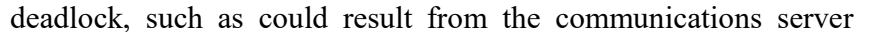

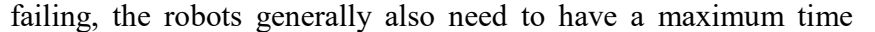

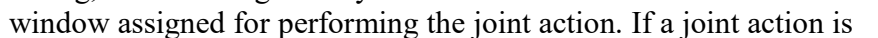

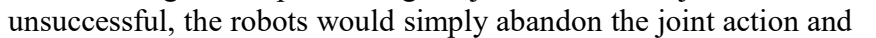

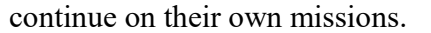

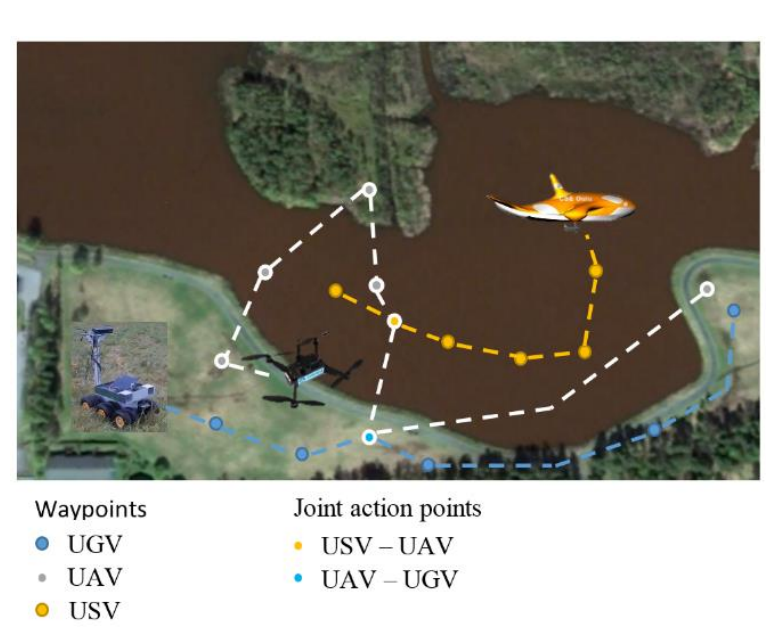

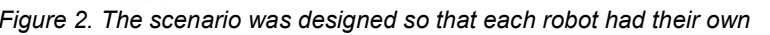

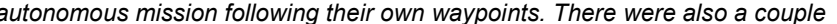

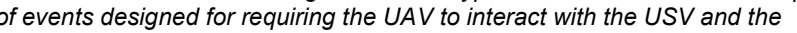

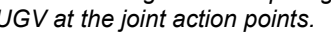

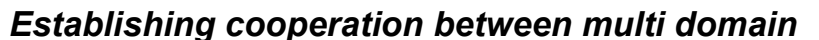

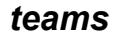

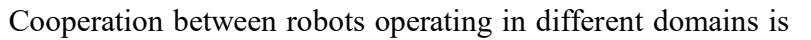

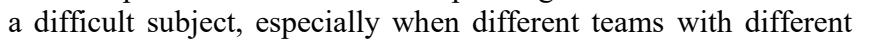

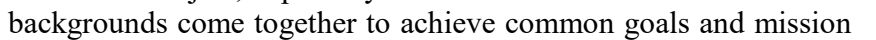

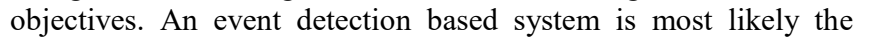

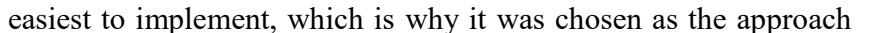

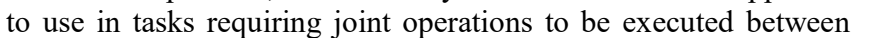

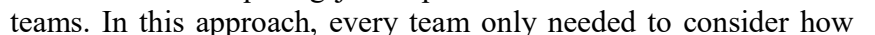

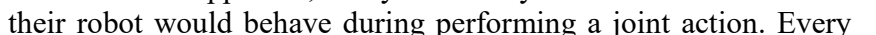

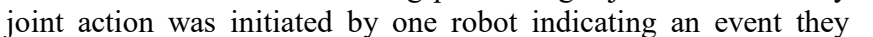

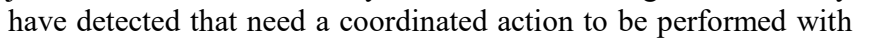

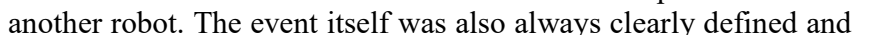

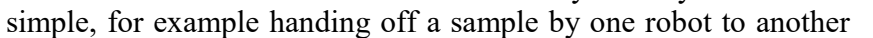

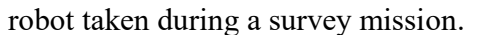

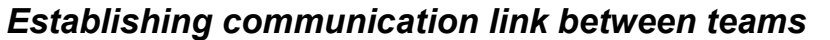

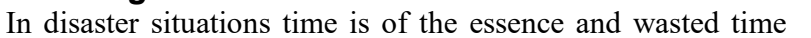

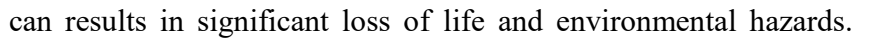

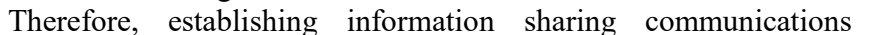

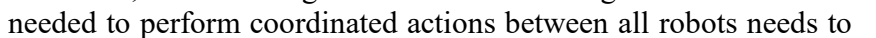

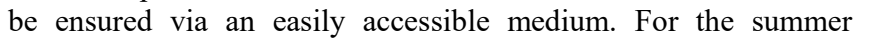

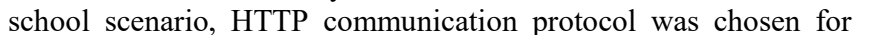

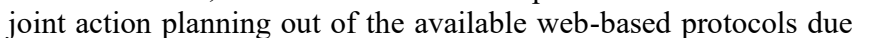

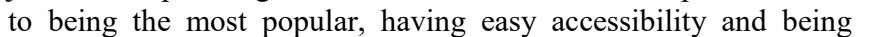

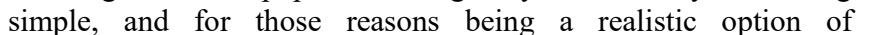

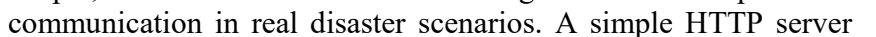

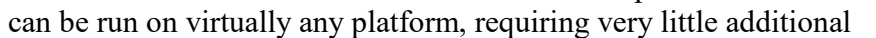

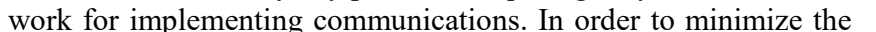

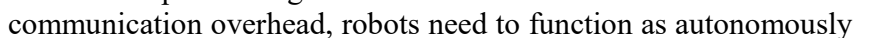

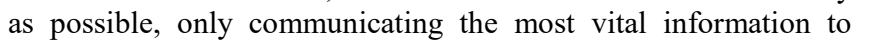

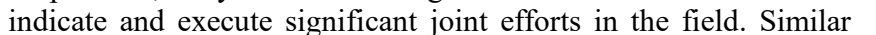

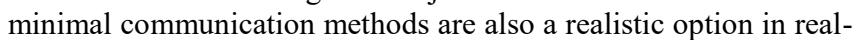

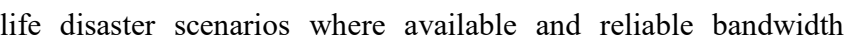

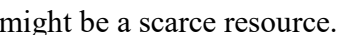

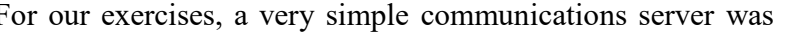
made using the Python programming language's

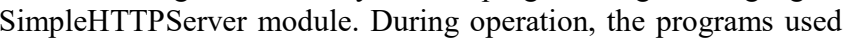

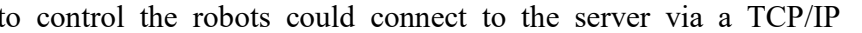

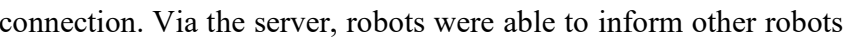

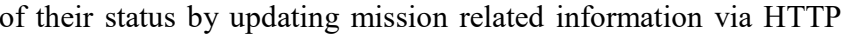

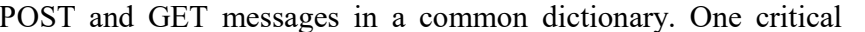

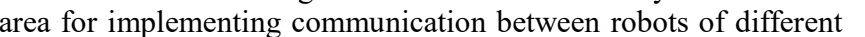

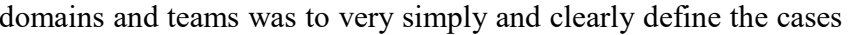

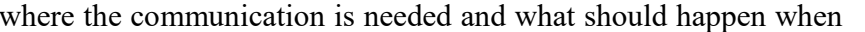

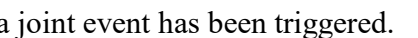

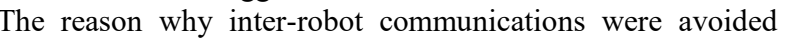

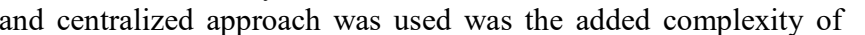

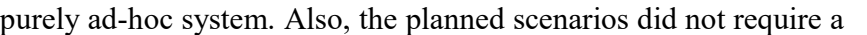

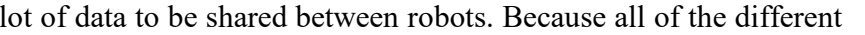

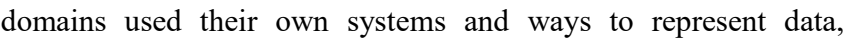

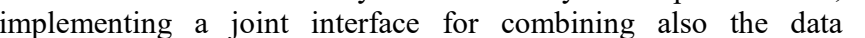

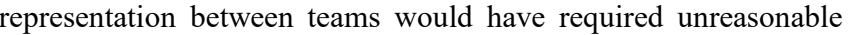

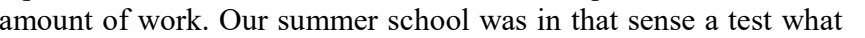

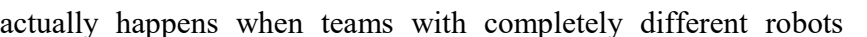

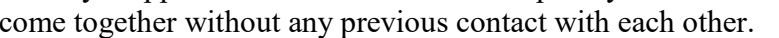

\section{Communication protocol}

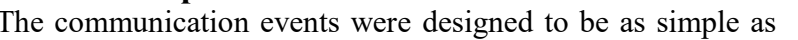

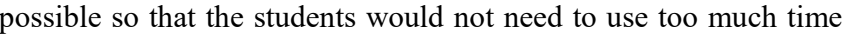

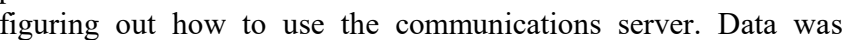

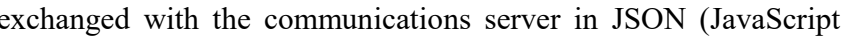

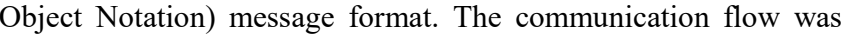

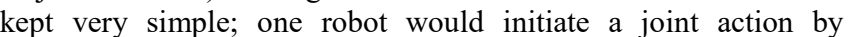

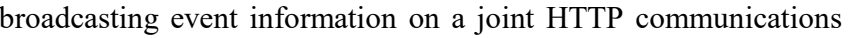

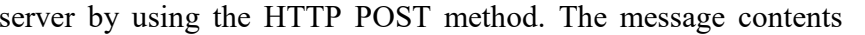

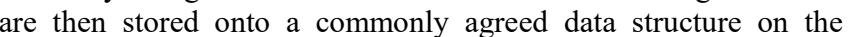

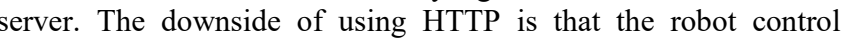

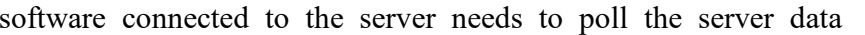

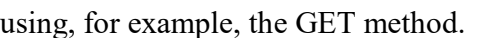

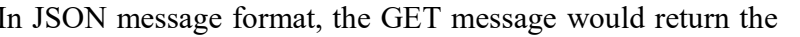

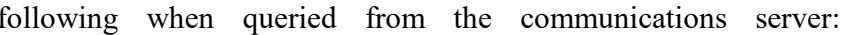

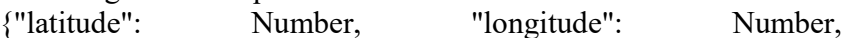

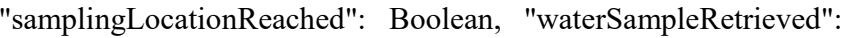

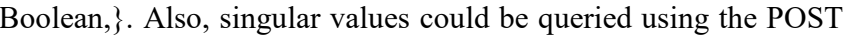

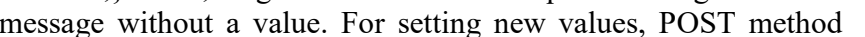

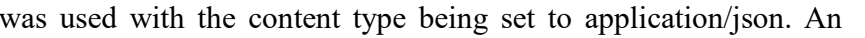

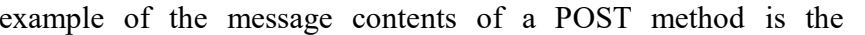

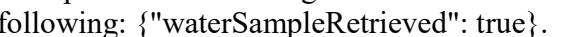

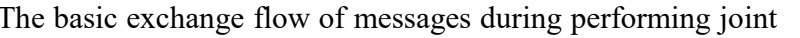

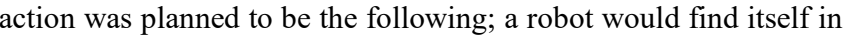

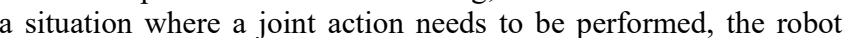

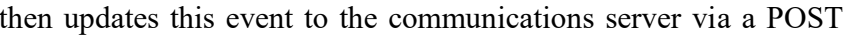
ロ

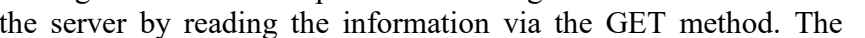

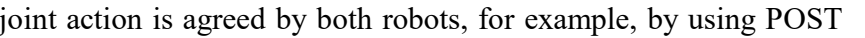

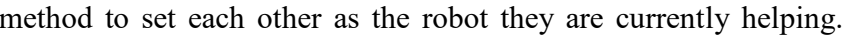

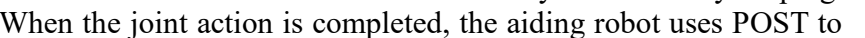

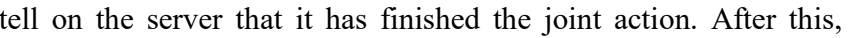

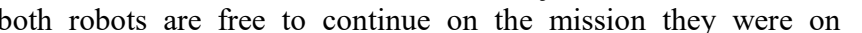

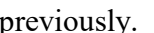

\section{Domain specific exercise implementations}

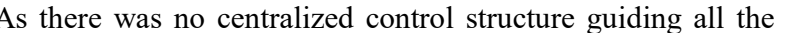

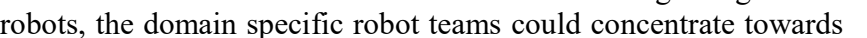

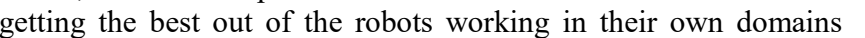




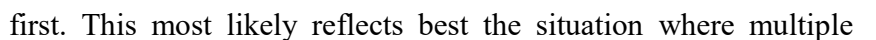

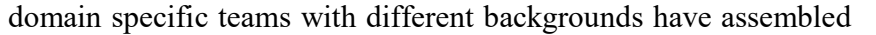

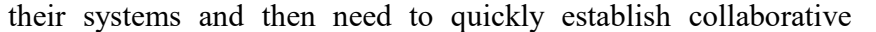

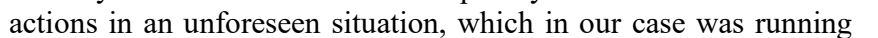

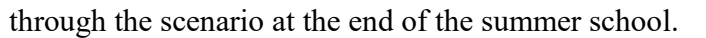

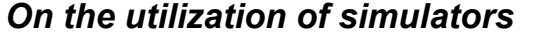

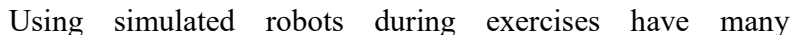

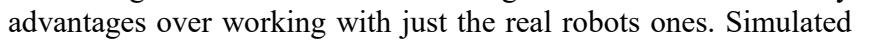
ए

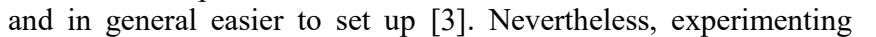

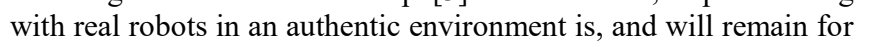

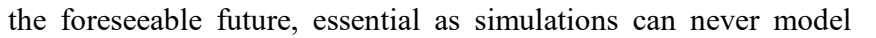

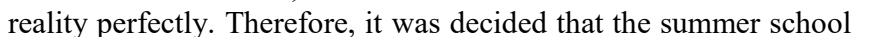

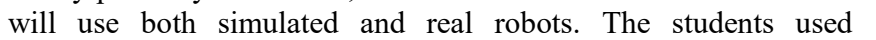

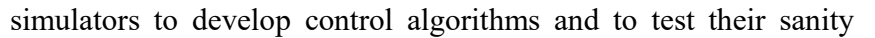

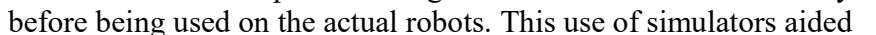

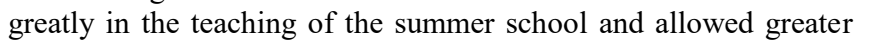
ए

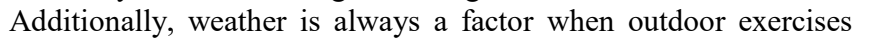

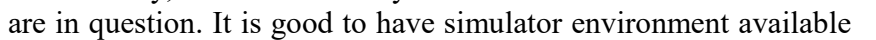
प

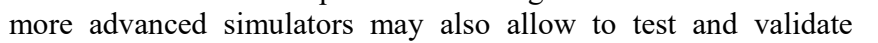

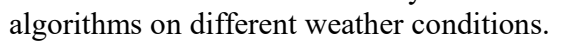

The simulations' proper level of abstraction should be

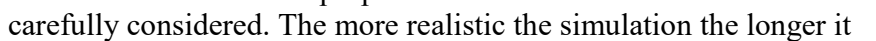

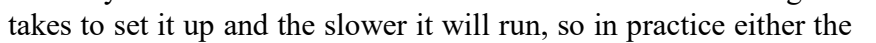

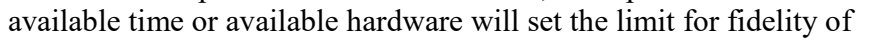

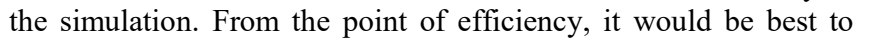

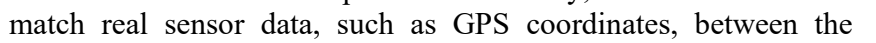

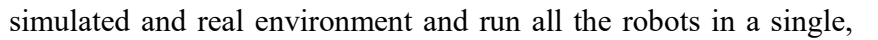

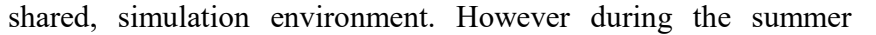

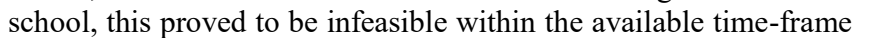

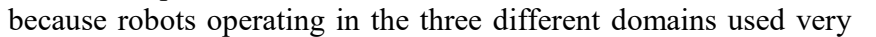

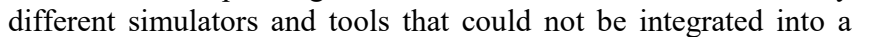

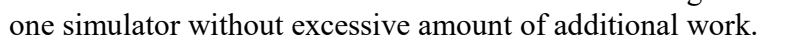

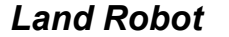

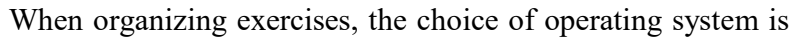

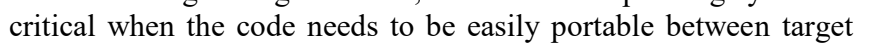

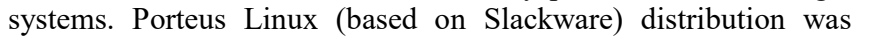

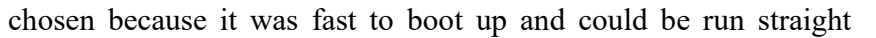
ए

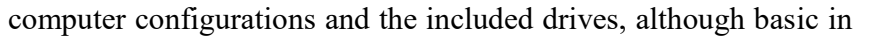

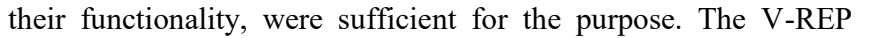

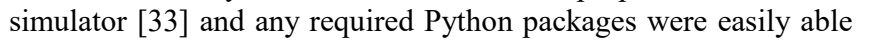
एण

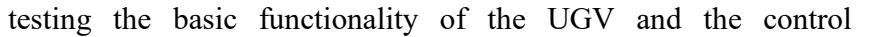

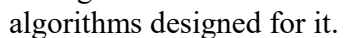

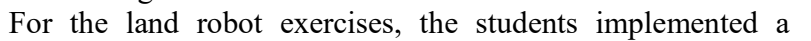

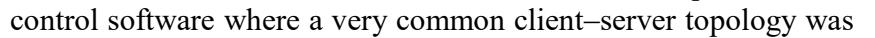

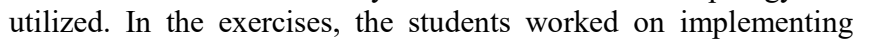

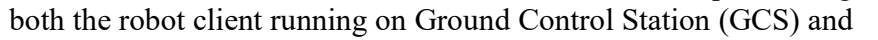

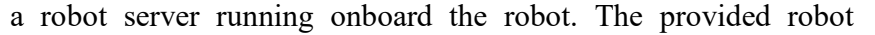

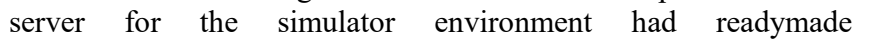
implementations for using some of the simulated robot's

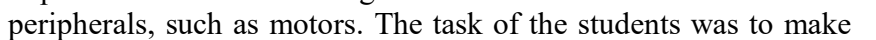
पा

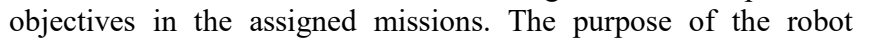

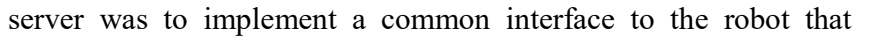

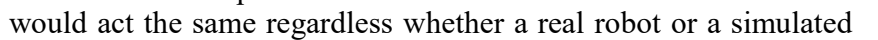

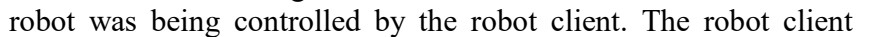

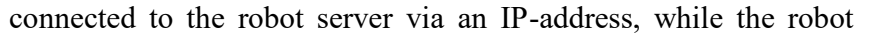

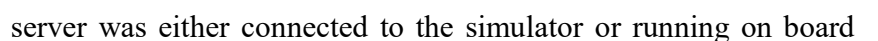
पe real robot controlling the robot's peripherals and motors. $\square$

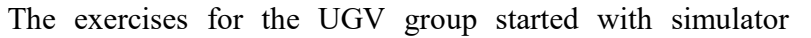

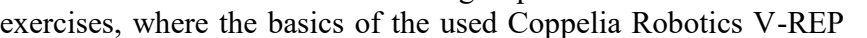

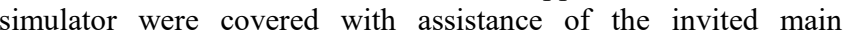

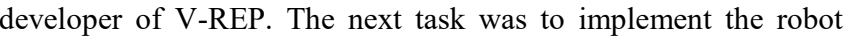

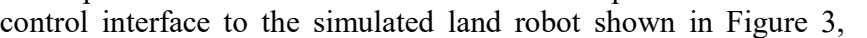

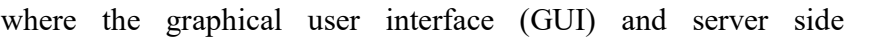

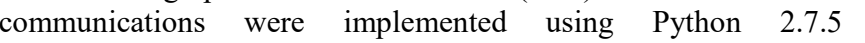

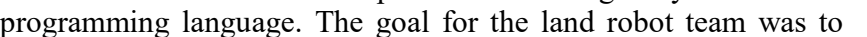

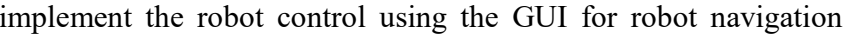

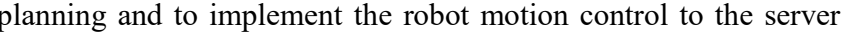

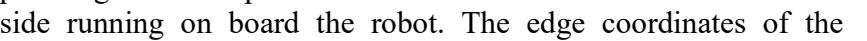

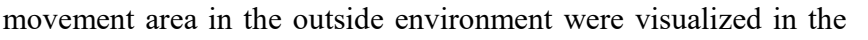

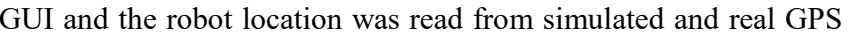

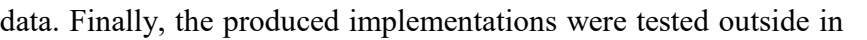

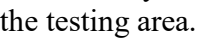

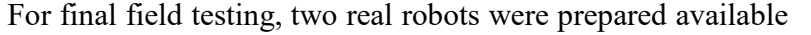

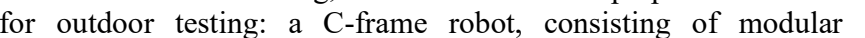

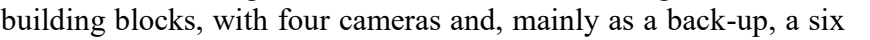

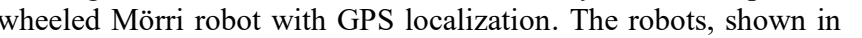

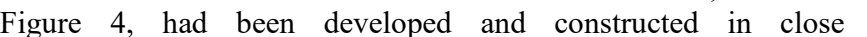

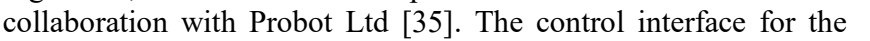

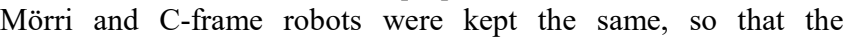

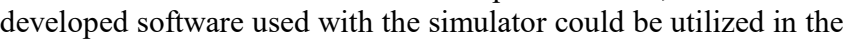

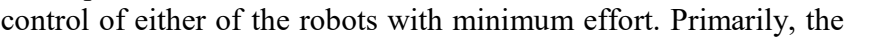

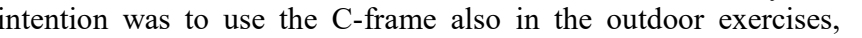

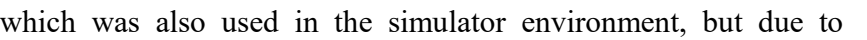

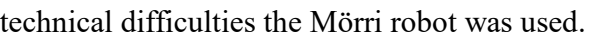

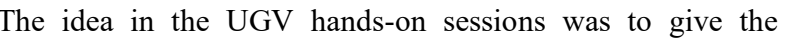

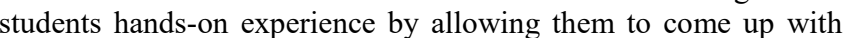

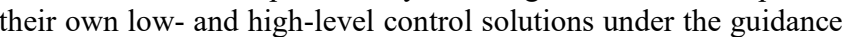

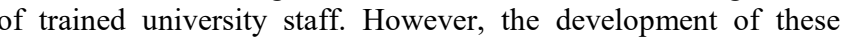

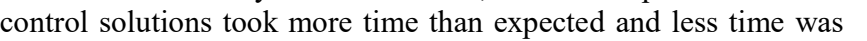

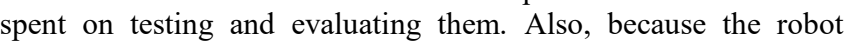

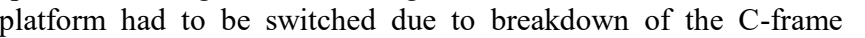

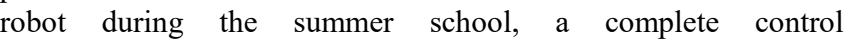

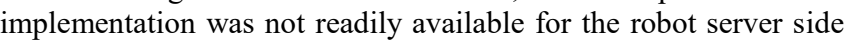

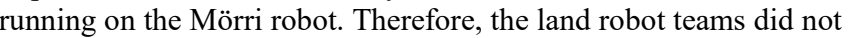

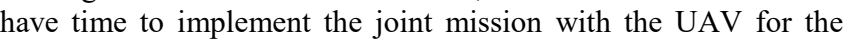

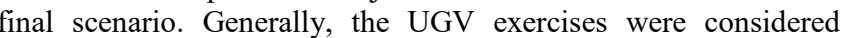

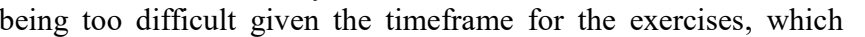

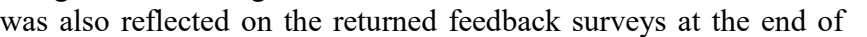

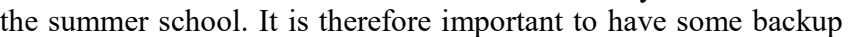

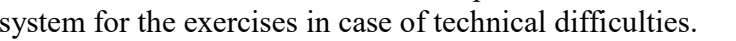

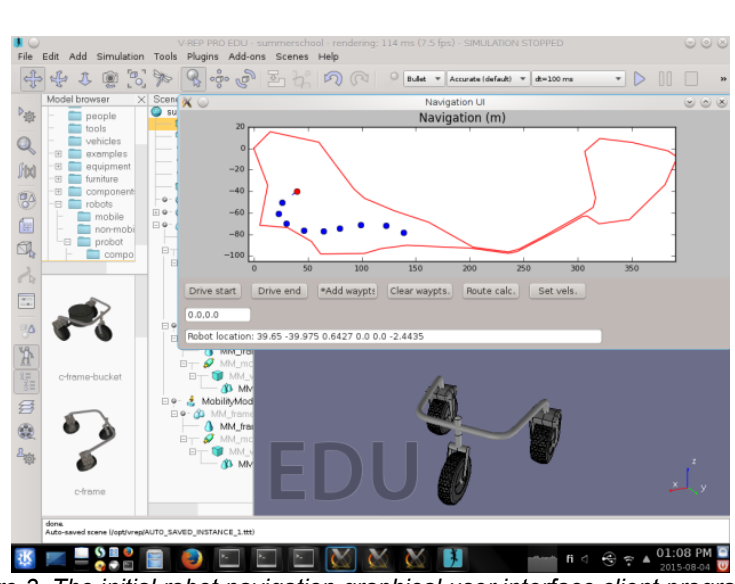

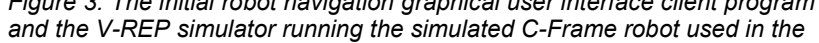




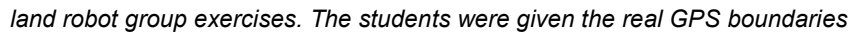

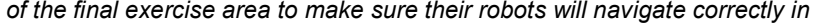

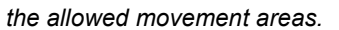

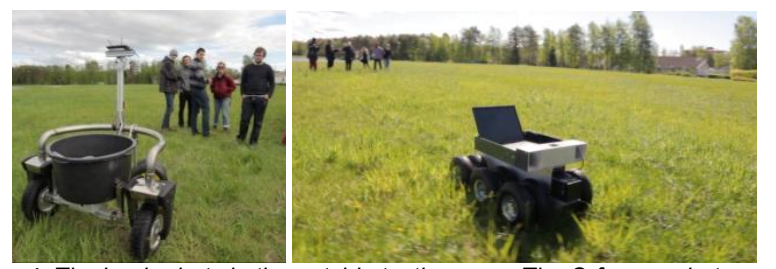

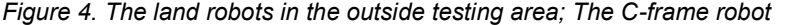

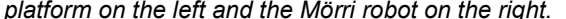

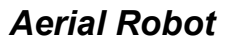

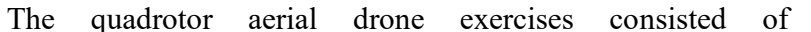

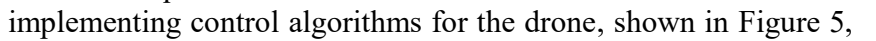

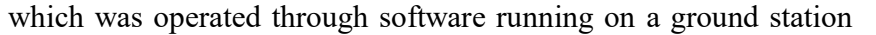

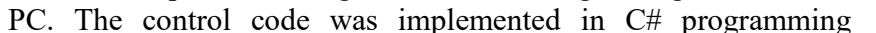

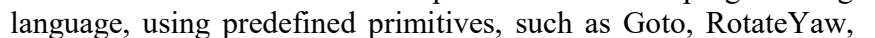

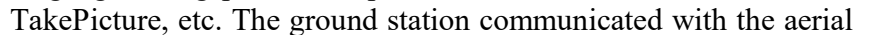

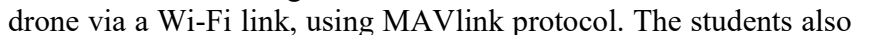

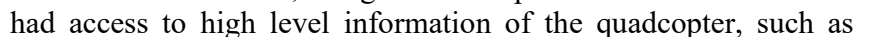

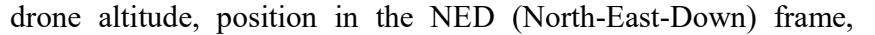

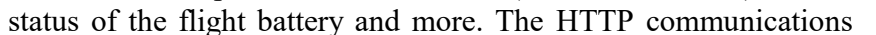

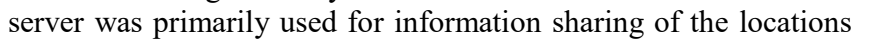

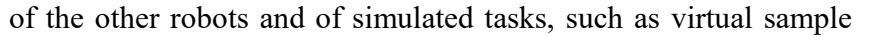

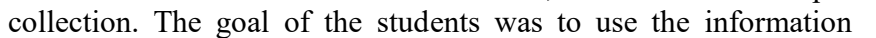

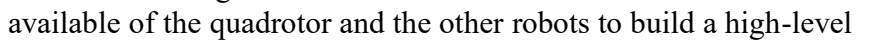

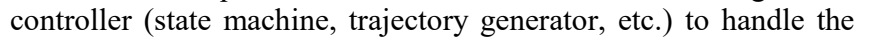

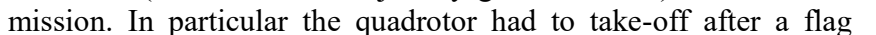

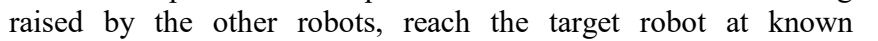
பा

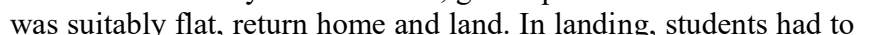

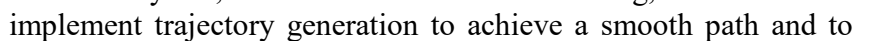

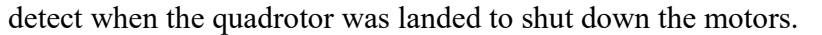

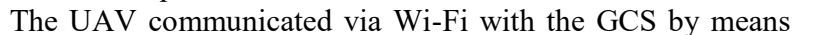

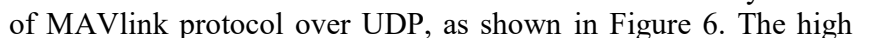

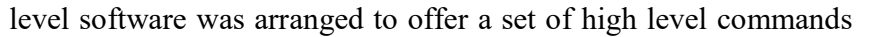

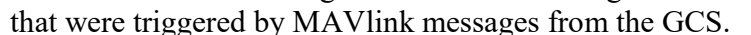

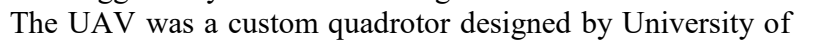

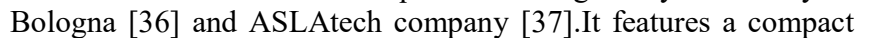

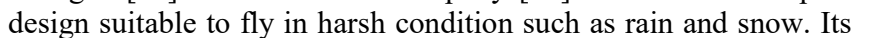

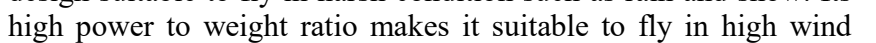

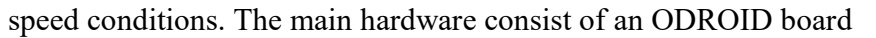

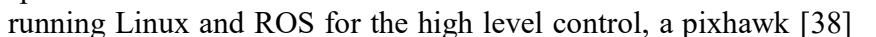

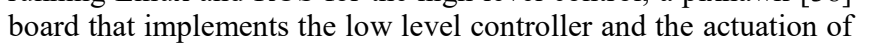
ए

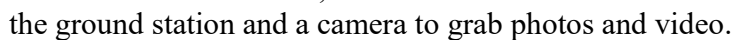

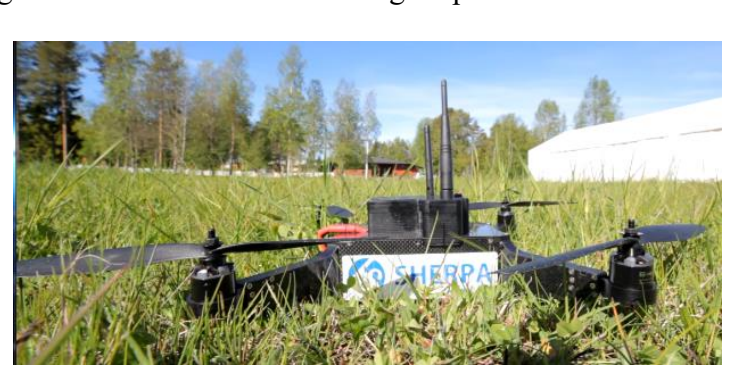

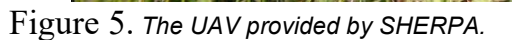

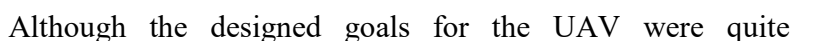

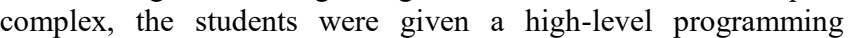

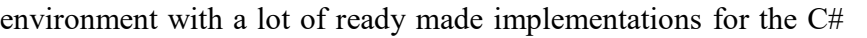

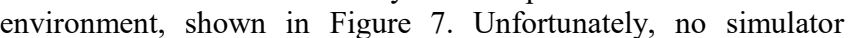

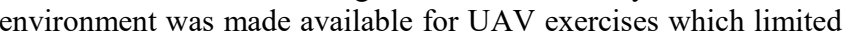

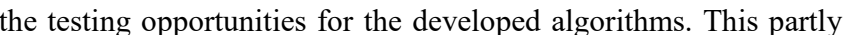

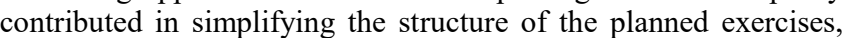

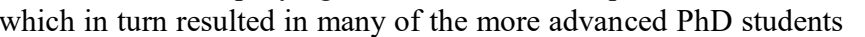

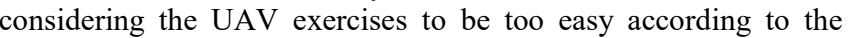

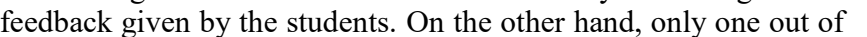

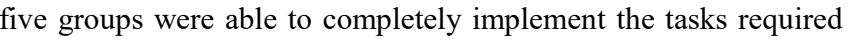
प

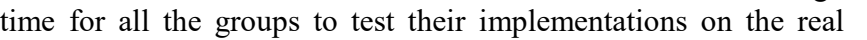

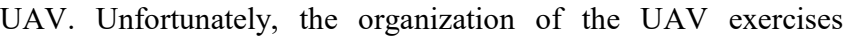

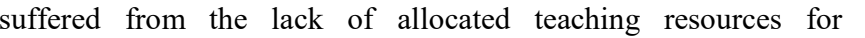

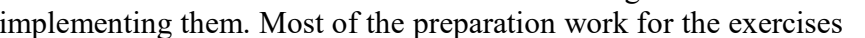

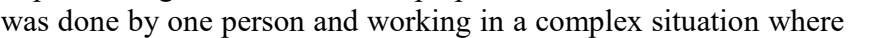

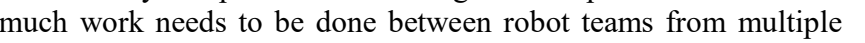

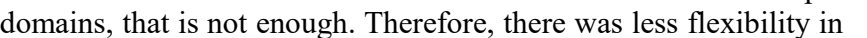

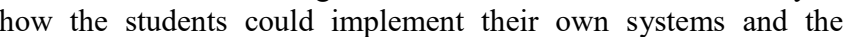

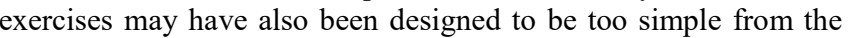

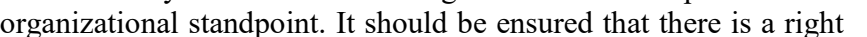

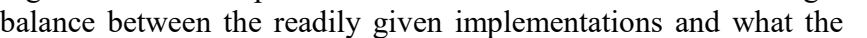

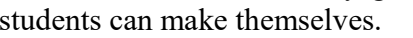

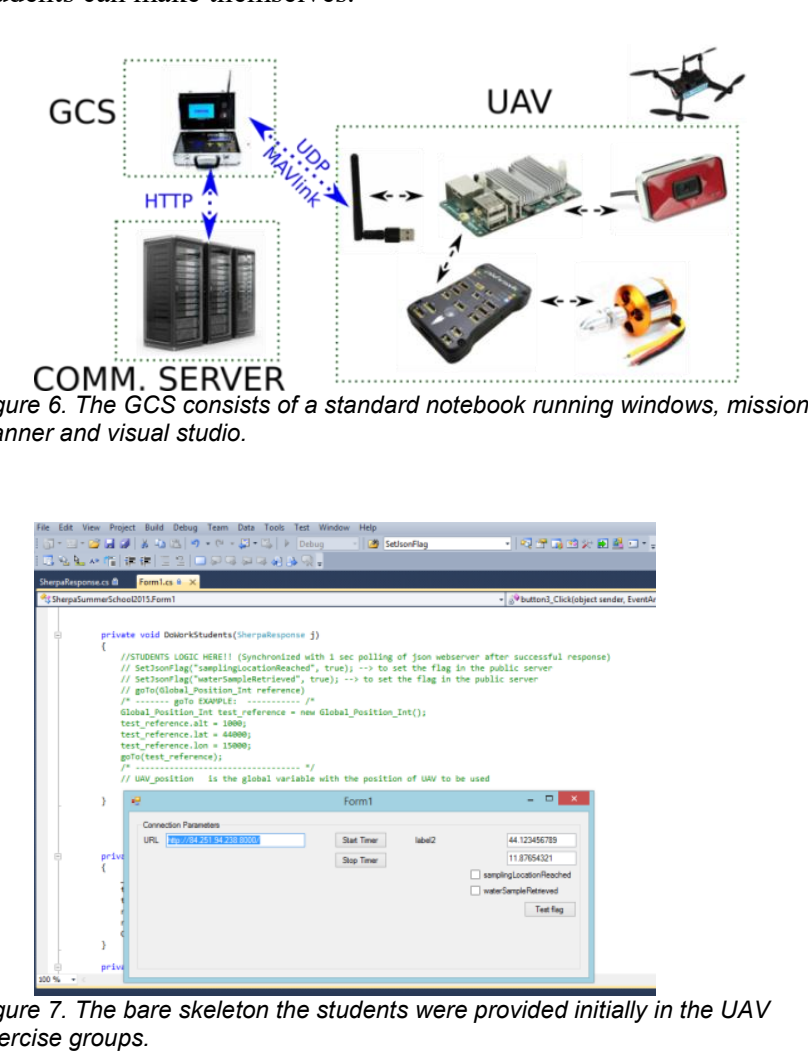

\section{Marine Robot}

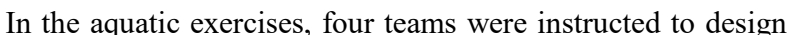

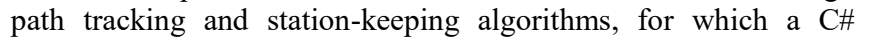
घu

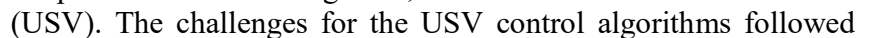

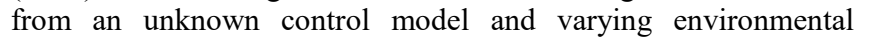

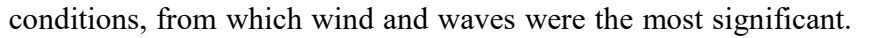




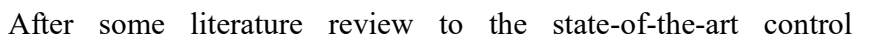

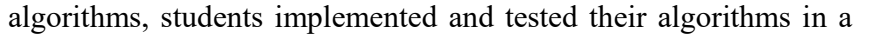

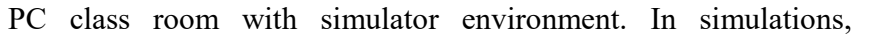

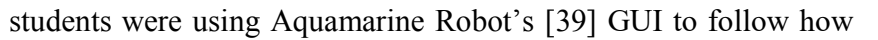

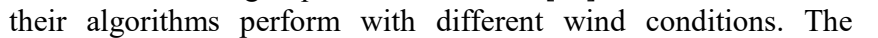

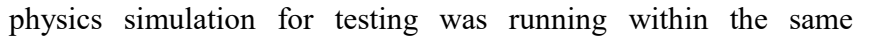

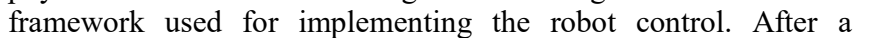

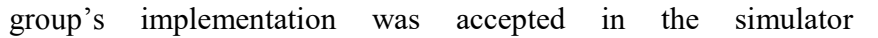

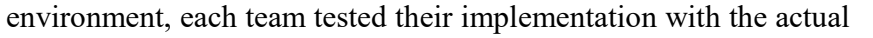
$\square \square \square \square$

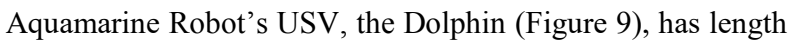

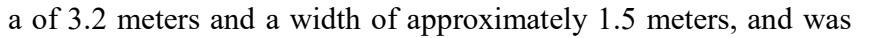

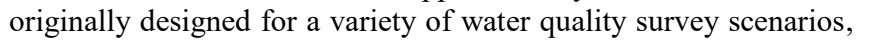

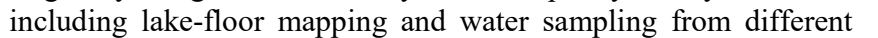

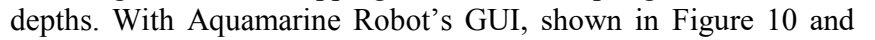

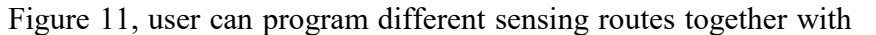

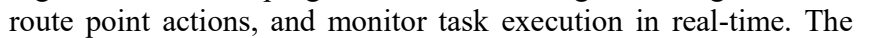

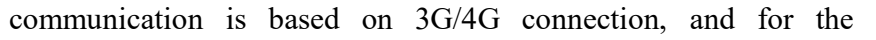

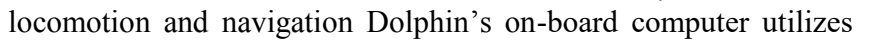

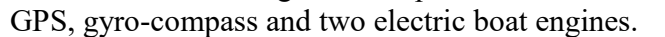

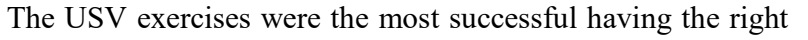

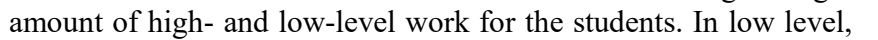

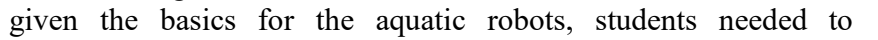

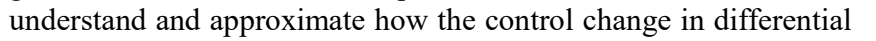

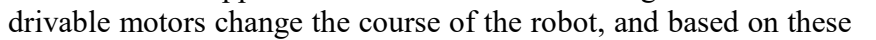

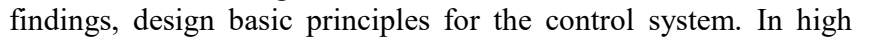

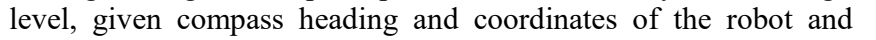

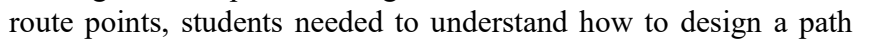

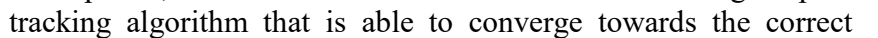

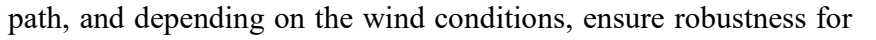

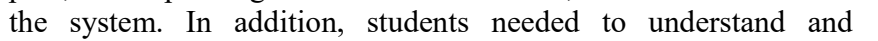

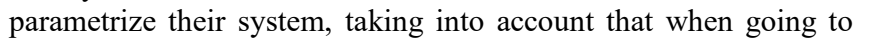

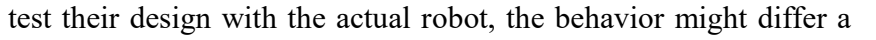

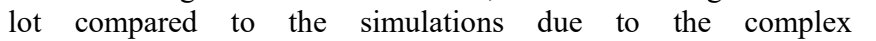

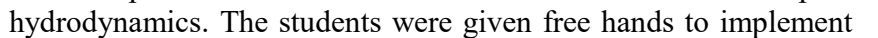

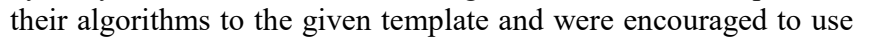

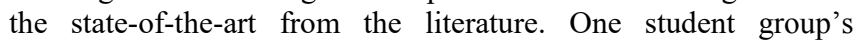
implementation actually surpassed the USV's original control पाए।

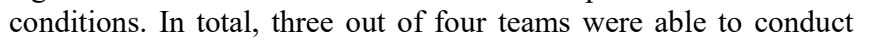

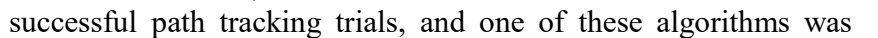

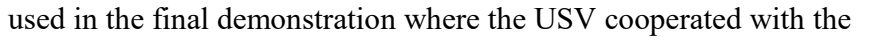
प्मणा

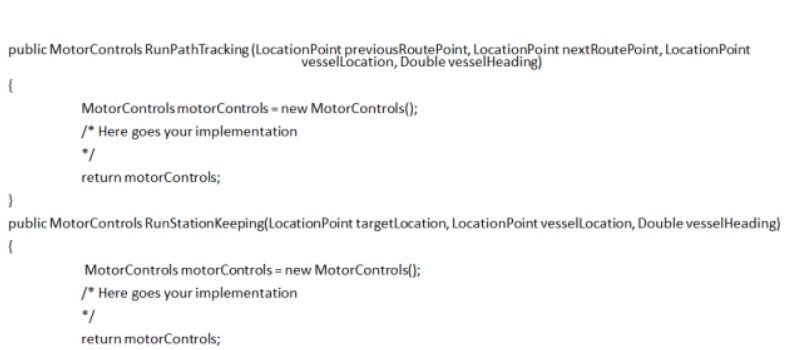

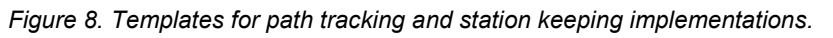

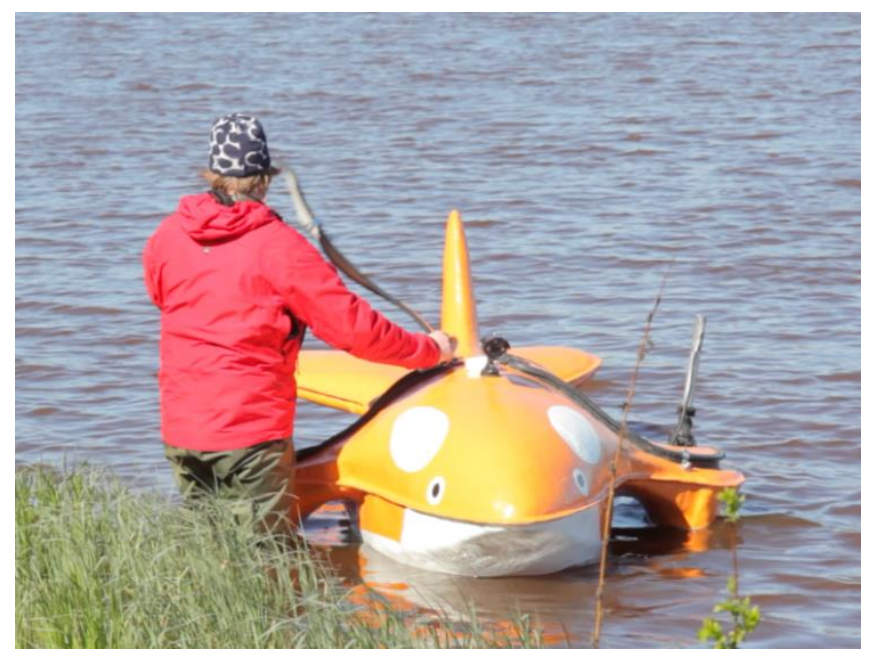

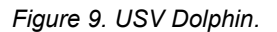

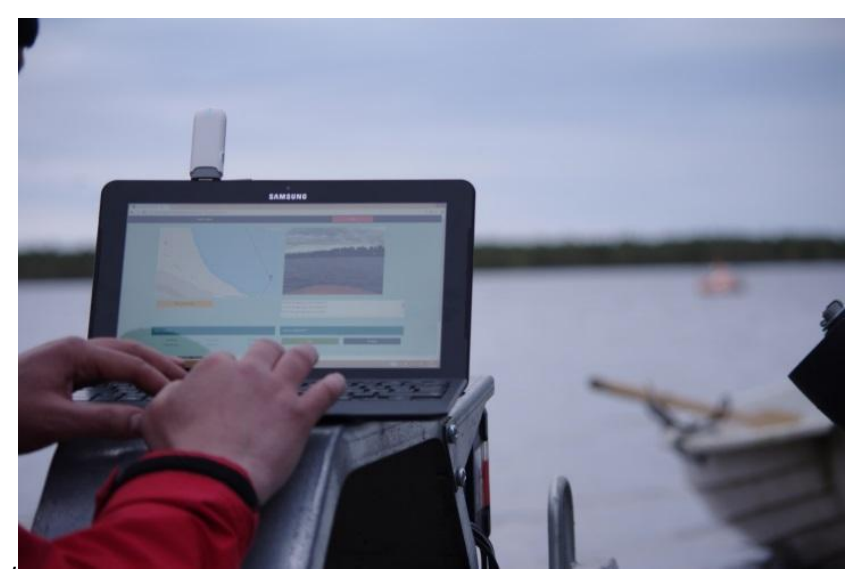

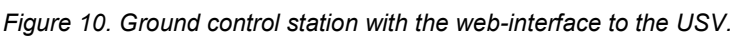

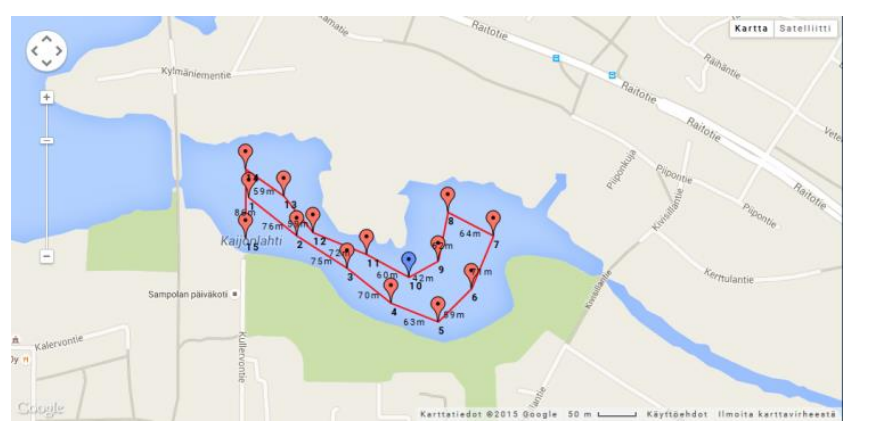

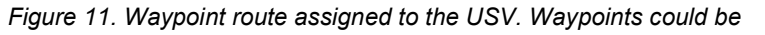

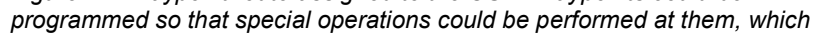

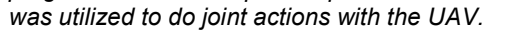

\section{Challenge Demonstration}

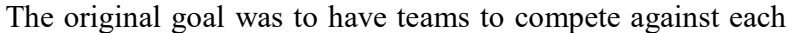

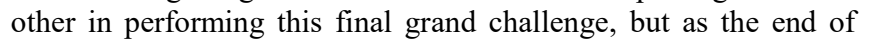

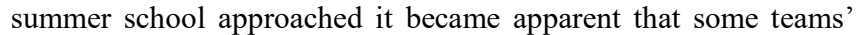

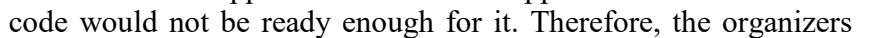




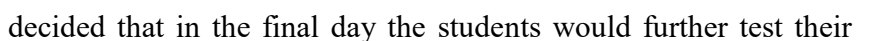

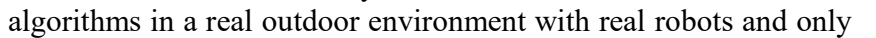

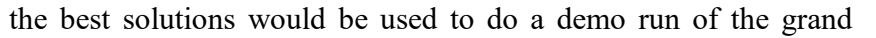

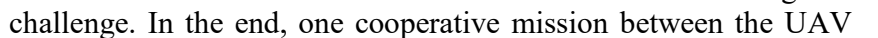

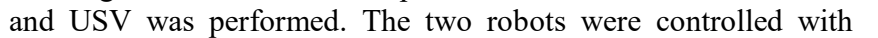

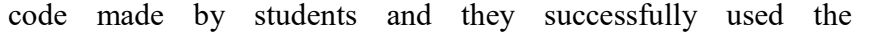

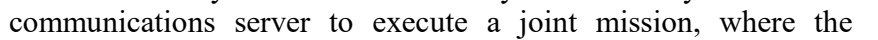

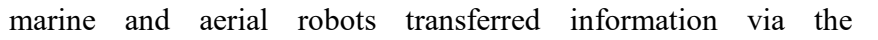

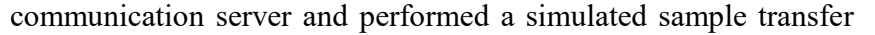

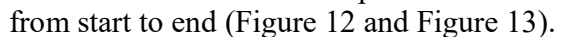

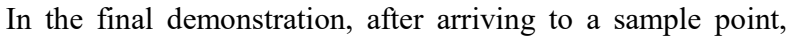
USV sent its coordinates and instruction to the UAV to 'pick up $\square \square$ ple' via the HTTP communications server. This was responded

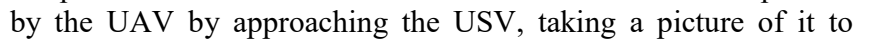

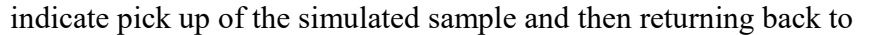

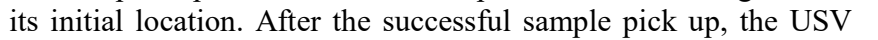

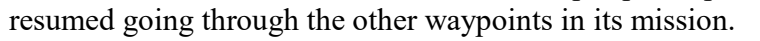

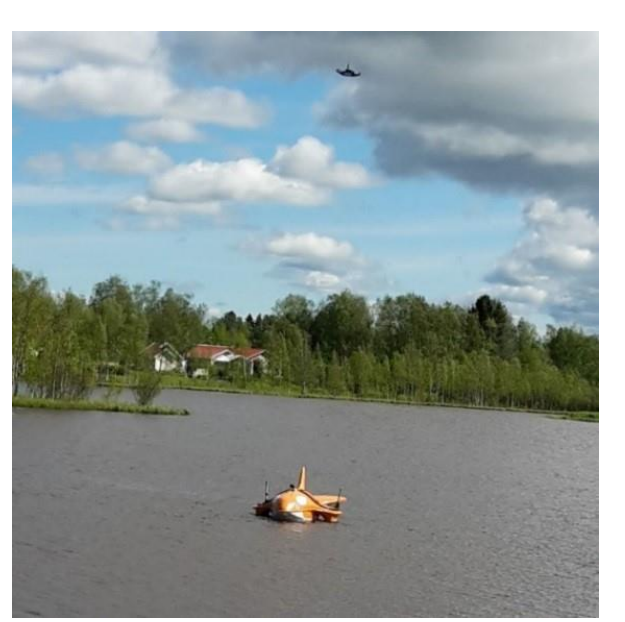

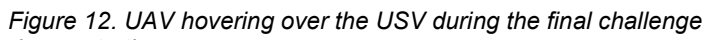

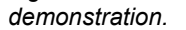

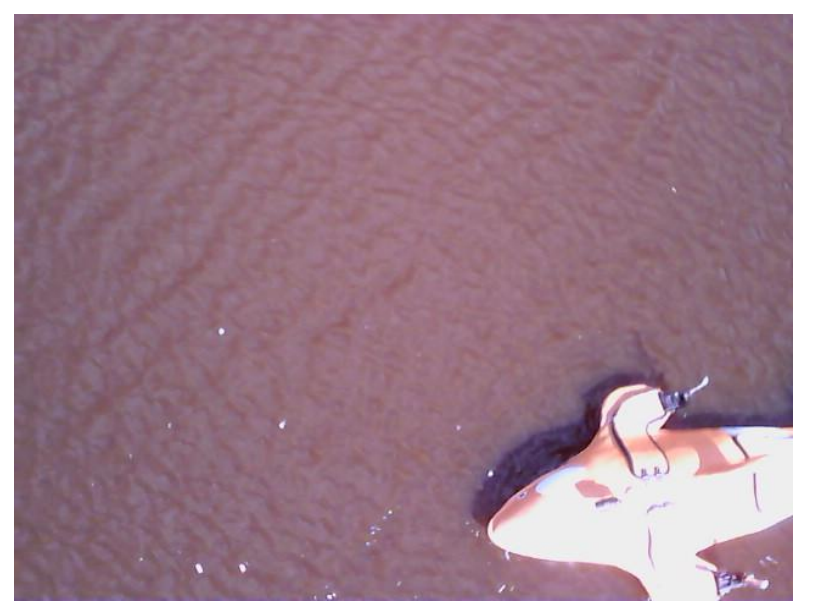

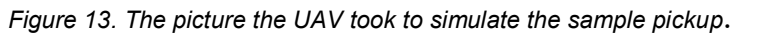

\section{Organizational Aspects}

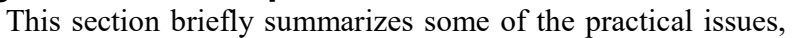

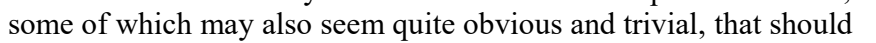

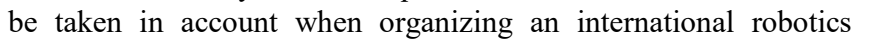

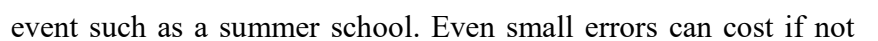

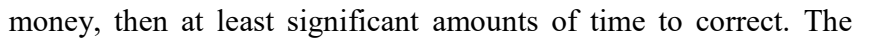

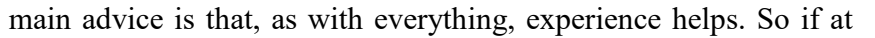

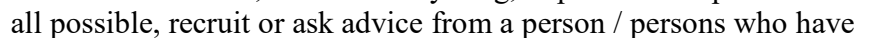

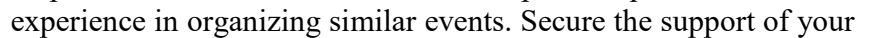

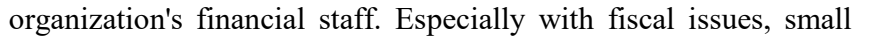

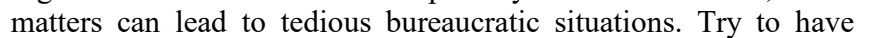

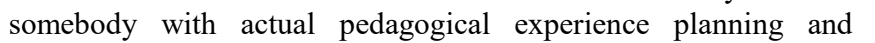
ए

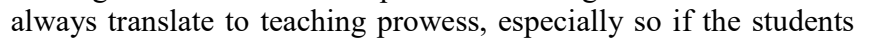

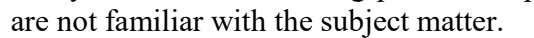

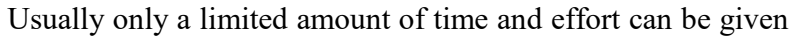
ए

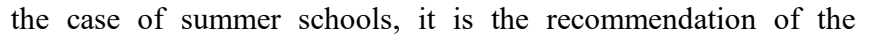

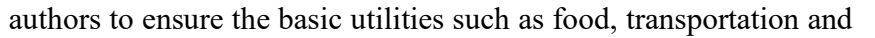

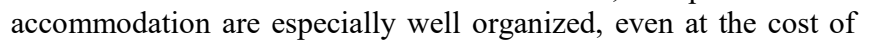

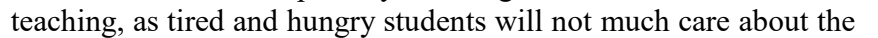

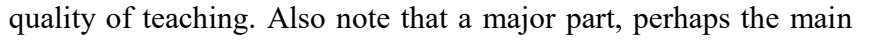

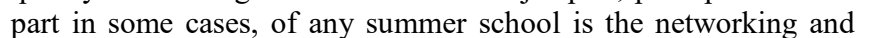

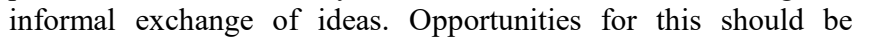

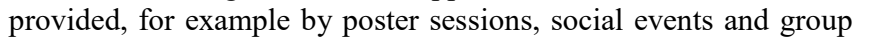

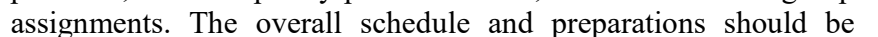

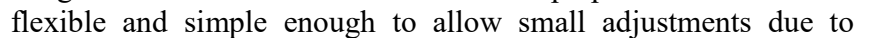

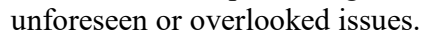

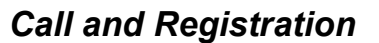

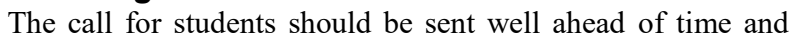
एाए

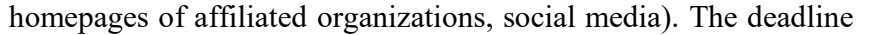

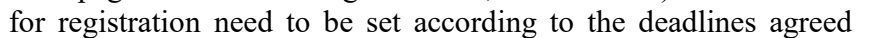

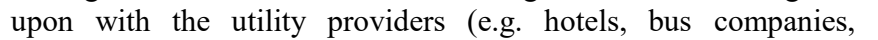

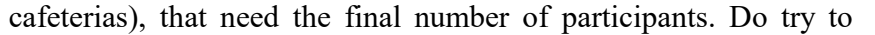

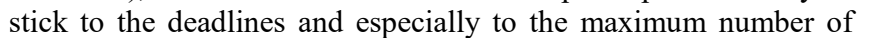

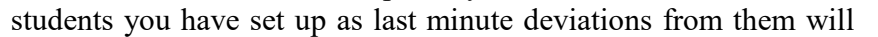

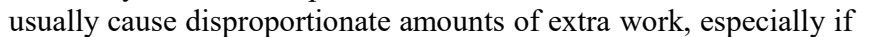

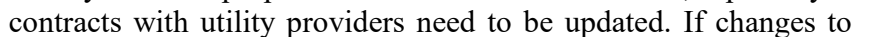

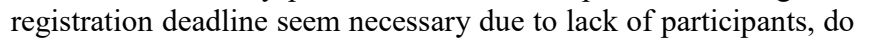

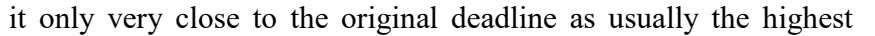

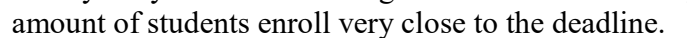

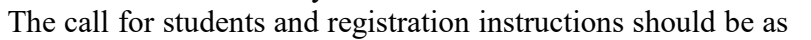

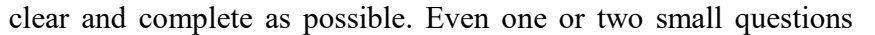

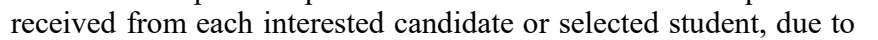

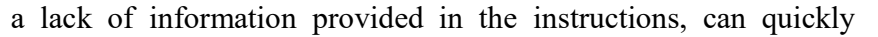

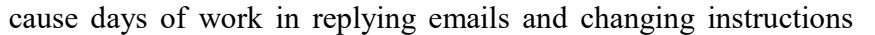

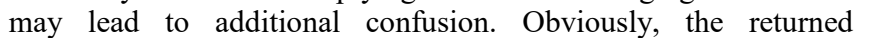

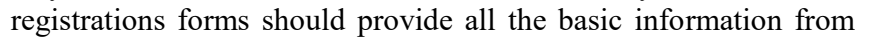

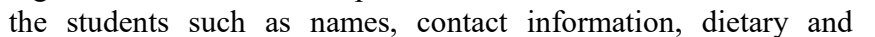

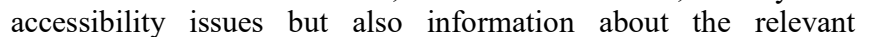
पा

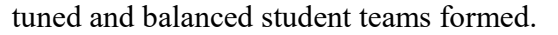

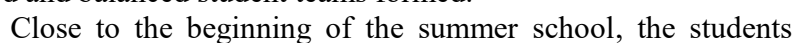

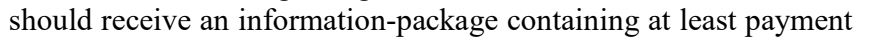

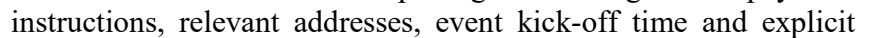

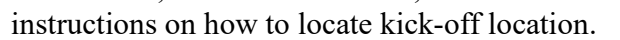

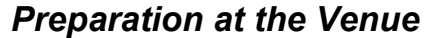

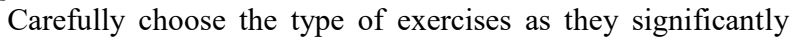

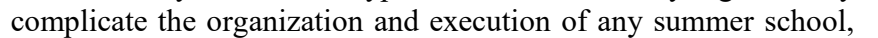

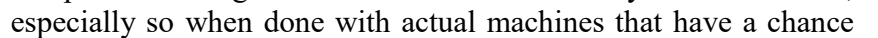

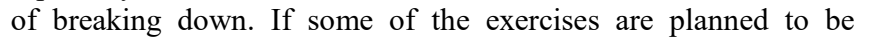

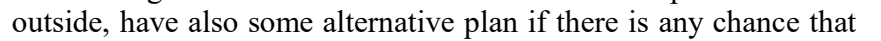

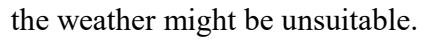




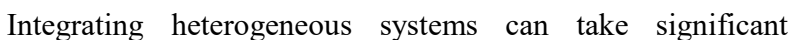
प

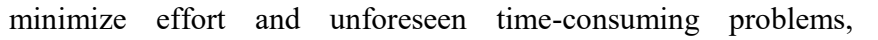

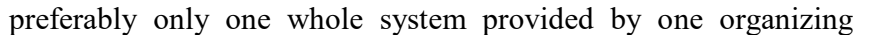

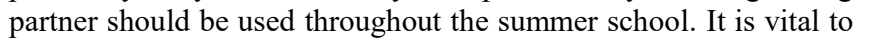

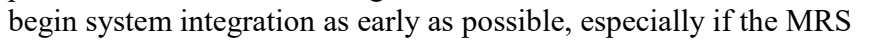

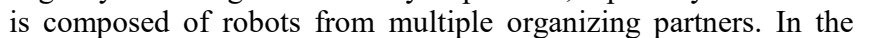

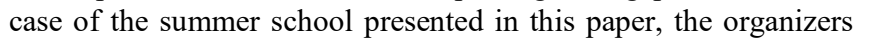

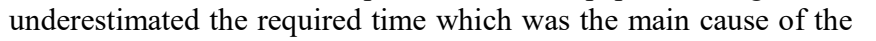

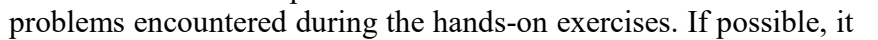

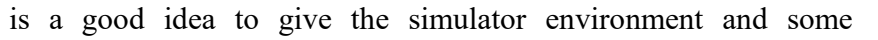

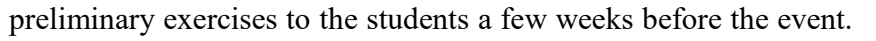

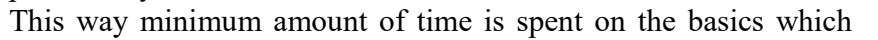

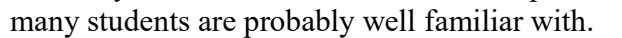

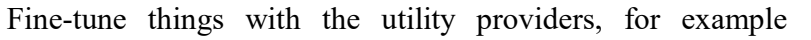

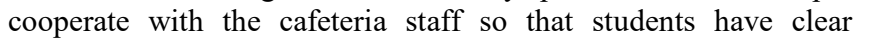

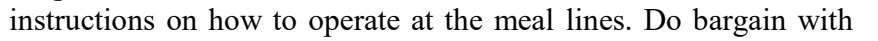

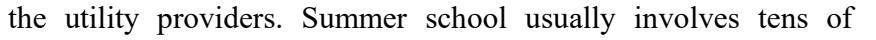

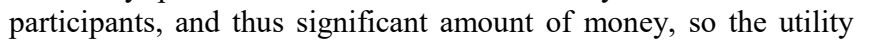

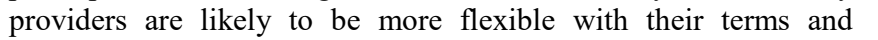

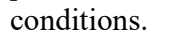

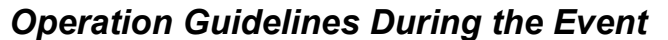

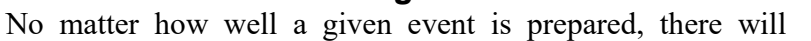

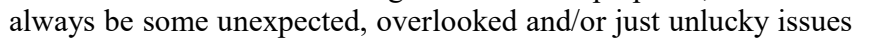

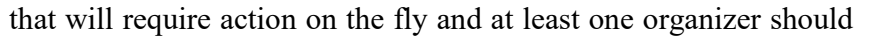

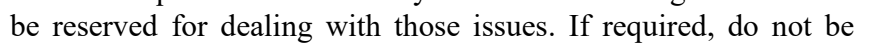

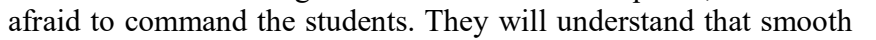

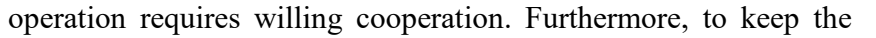

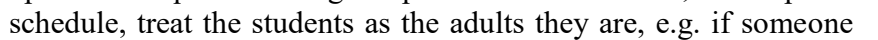

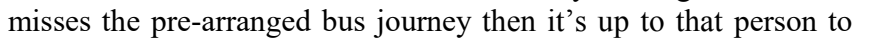

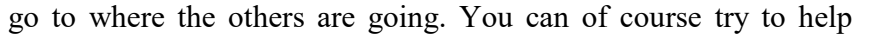

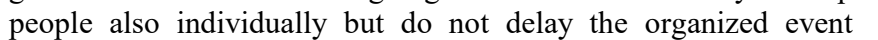

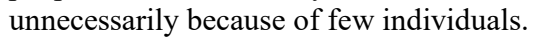

\section{Final Thoughts}

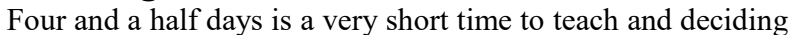

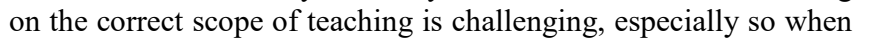

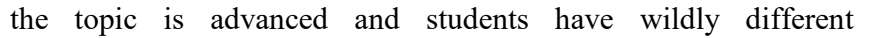

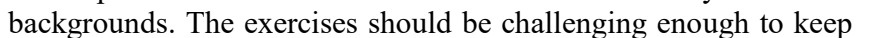

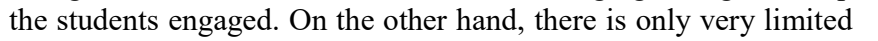

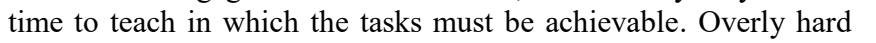

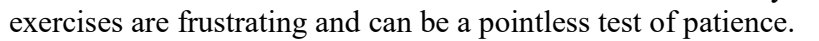

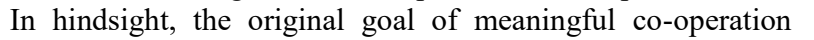

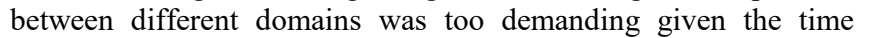
ए

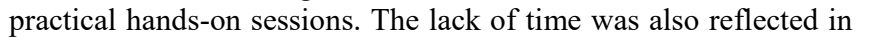

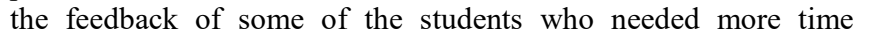

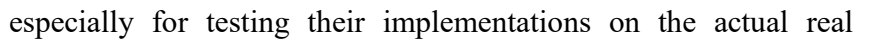
ए

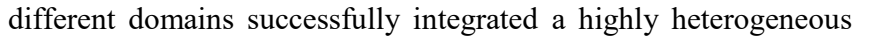

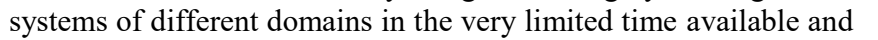

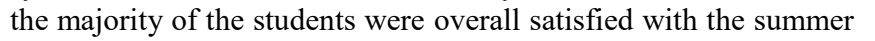

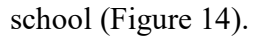

$\square$

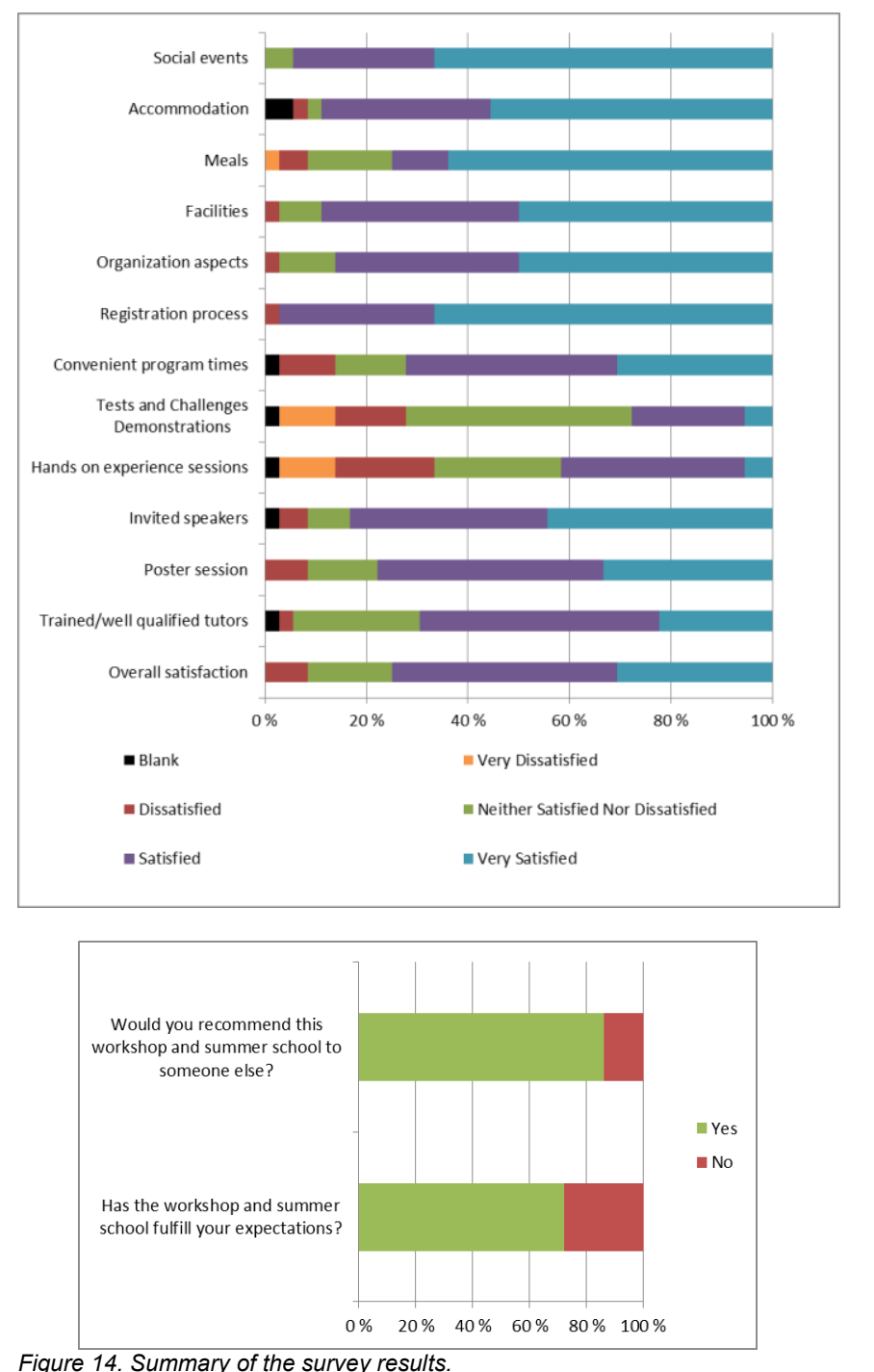

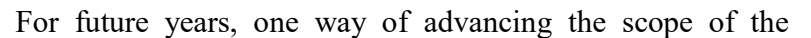

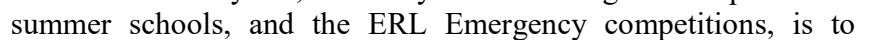

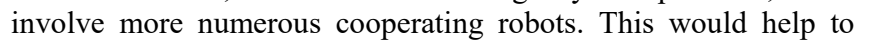

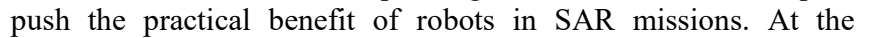

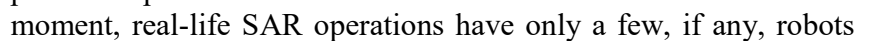

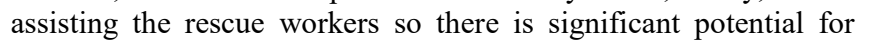
口

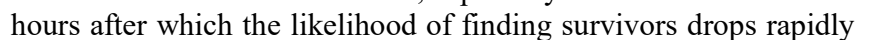

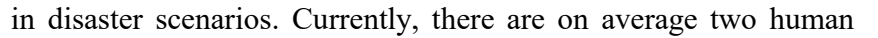

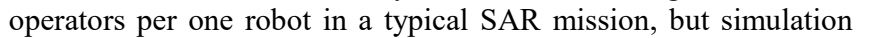

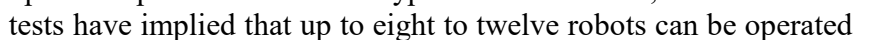

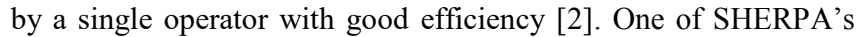

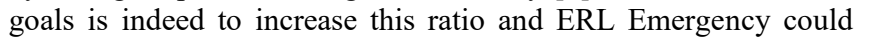

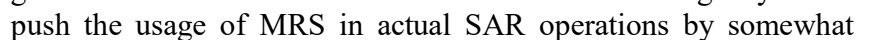

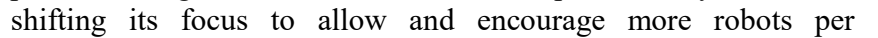

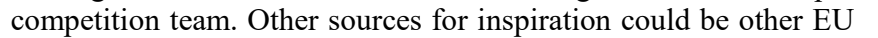

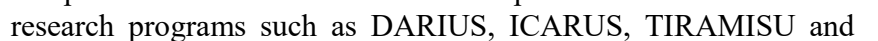
प्रणमणा

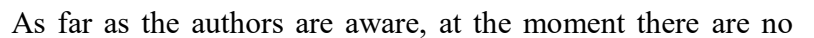

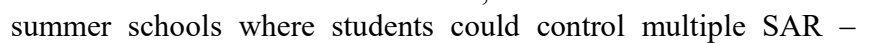

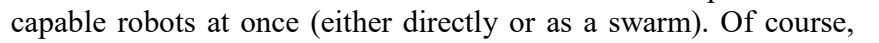




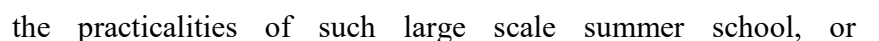

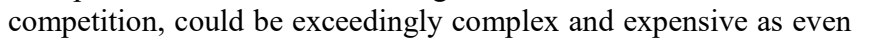

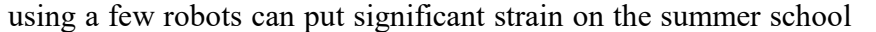

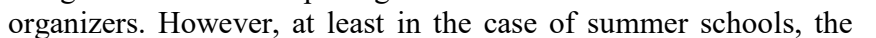

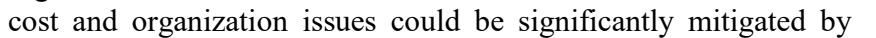

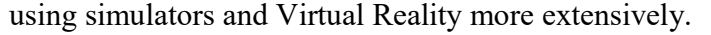

\section{References}

पा

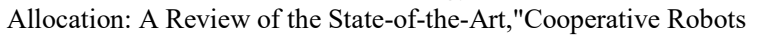

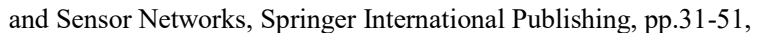
$\square 110$

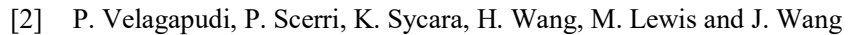

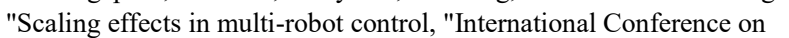

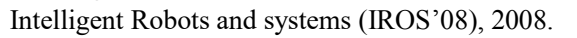

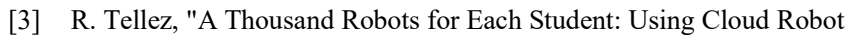

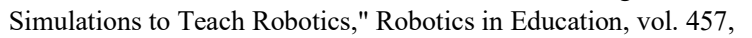
पाणाणापाणाणा

एण

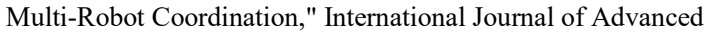

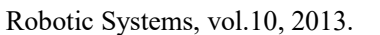

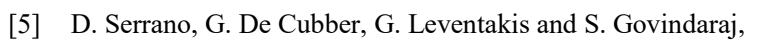

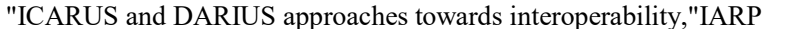

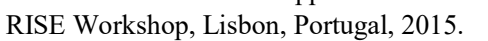

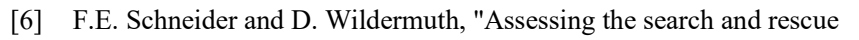

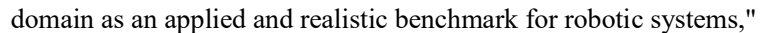

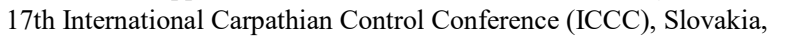
पाणाण

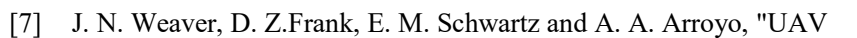

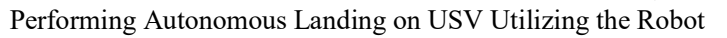

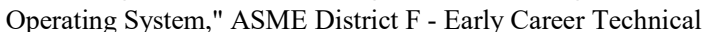

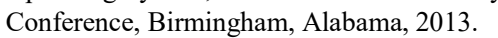

एण

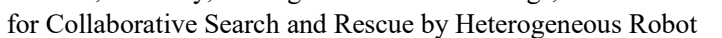

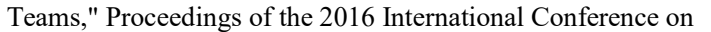

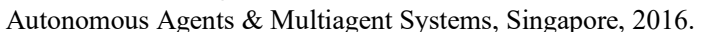

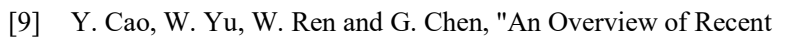

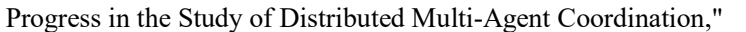

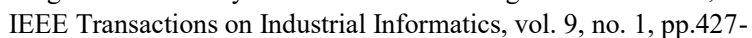

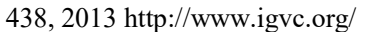

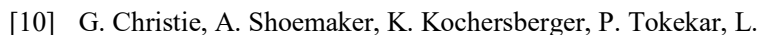

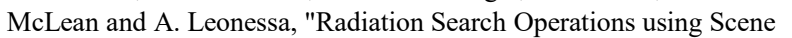

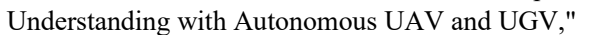

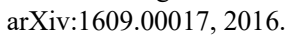

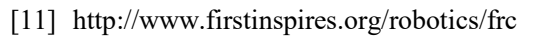

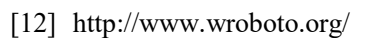

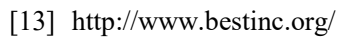

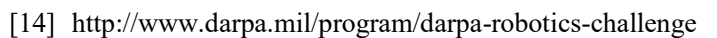

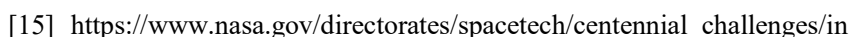
पाणाणा प्रा

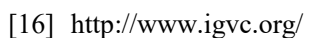

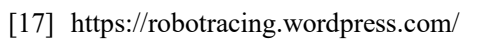

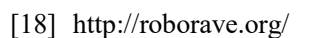

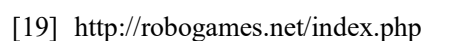

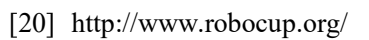

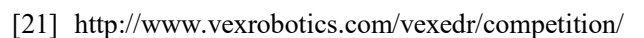

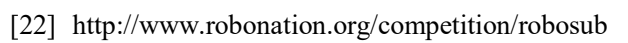

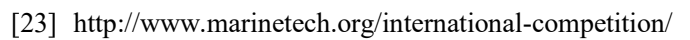

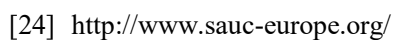

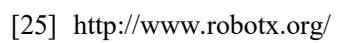

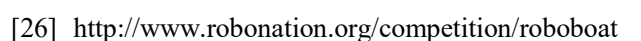

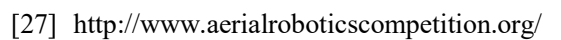

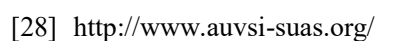

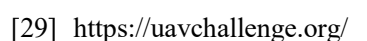

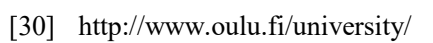

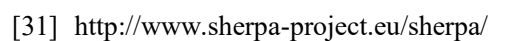

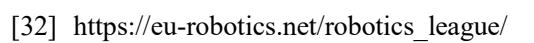

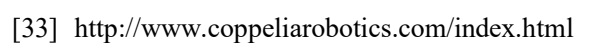

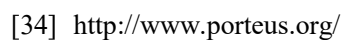

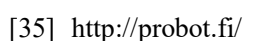

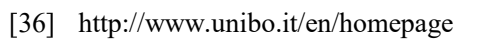

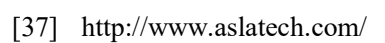

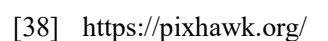

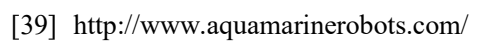

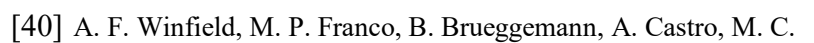

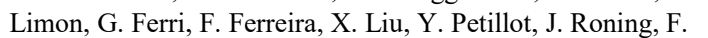

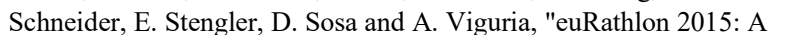

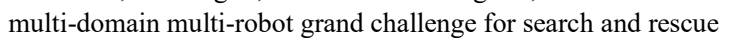
एव

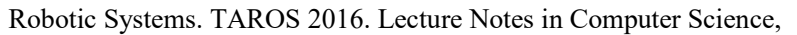

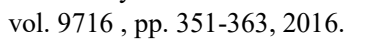

\section{$\square$}

